IZA DP No. 7128

Unemployment Insurance, Wage Dynamics and Inequality over the Life Cycle

Paul Bingley

Lorenzo Cappellari

Niels Westergård-Nielsen

January 2013 


\title{
Unemployment Insurance, Wage Dynamics and Inequality over the Life Cycle
}

\author{
Paul Bingley \\ SFI - The Danish National Centre for Social Research \\ Lorenzo Cappellari \\ Università Cattolica Milano \\ and IZA \\ Niels Westergård-Nielsen \\ $C C P$, Aarhus University \\ and IZA
}

Discussion Paper No. 7128

January 2013

IZA

P.O. Box 7240

53072 Bonn

Germany

Phone: +49-228-3894-0

Fax: +49-228-3894-180

E-mail: iza@iza.org

Any opinions expressed here are those of the author(s) and not those of IZA. Research published in this series may include views on policy, but the institute itself takes no institutional policy positions. The IZA research network is committed to the IZA Guiding Principles of Research Integrity.

The Institute for the Study of Labor (IZA) in Bonn is a local and virtual international research center and a place of communication between science, politics and business. IZA is an independent nonprofit organization supported by Deutsche Post Foundation. The center is associated with the University of Bonn and offers a stimulating research environment through its international network, workshops and conferences, data service, project support, research visits and doctoral program. IZA engages in (i) original and internationally competitive research in all fields of labor economics, (ii) development of policy concepts, and (iii) dissemination of research results and concepts to the interested public.

IZA Discussion Papers often represent preliminary work and are circulated to encourage discussion. Citation of such a paper should account for its provisional character. A revised version may be available directly from the author. 


\section{ABSTRACT}

\section{Unemployment Insurance, Wage Dynamics and Inequality over the Life Cycle*}

We investigate the relationship between life cycle wages and individual membership of unemployment insurance schemes in Denmark. We separate permanent from transitory wages and characterise them using membership of unemployment insurance funds. We find that unemployment insurance is associated with lower wage growth heterogeneity over the life cycle and greater wage instability, changing the nature of wage inequality from permanent to transitory. While we are in general unable to formally test for moral hazard against adverse selection into unemployment insurance, robustness checks suggest that moral hazard is the relevant interpretation.

JEL Classification: J31, J65

Keywords: $\quad$ unemployment insurance, wage dynamics, wage inequality, wage instability

Corresponding author:

Lorenzo Cappellari

Università Cattolica Milano

Largo Gemelli 1

20123 Milano

Italy

E-mail: Iorenzo.cappellari@unicatt.it

\footnotetext{
* A previous version of this paper was circulated as CESIfo working paper 3561 with the title "Flexicurity, wage dynamics and inequality over the life-cycle". We thank Astrid Gamba, Luigi Pistaferri, three anonymous referees and seminar participants at EALE 2009 Tallinn Conference, ESPE 2010 Essen Conference, RES 2012 Cambridge Conference, the IZA Workshop on "Unemployment Insurance and Flexicurity", the ZEW Workshop on "Flexibility in Heterogeneous Labour Markets", the Italian Treasury, Wurzburg and BeNA Berlin for useful comments. Cappellari gratefully acknowledges the hospitality of the Centre for Corporate Performance in Aarhus and the Danish National Centre for Social Research in Copenhagen. The usual disclaimers apply.
} 


\section{NON-TECHNICAL SUMMARY}

Unemployment insurance and unemployment benefits are generally recognised as key policy complements of reduced employment protection. The Danish "flexicurity" system is one of the main examples of such philosophy: firms are free to hire and fire, but an extended social safety net eliminates poverty risk and preserves social cohesion.

There is an extensive literature documenting that unemployment insurance may exert a disincentive on the job search effort of unemployment individuals. This literature generally finds that unemployment benefits may increase unemployment durations. There are also reasons to believe that unemployment insurance may affect productivity and wage dynamics of the employed, but these effects haven't been investigated so far.

We complement the literature by studying the effects of unemployment insurance on individual wage dynamics. By lowering the employee costs of being fired, unemployment insurance may reduce workers' effort and the associated learning-by-doing. The insured would thereby exhibit less wage growth over time. In the limit, low effort may result in a job loss, increasing job instability and the volatility of income over time.

We study these effects using data on the population of Danish men between 1980-2003. We find that both effects are at play: individuals who are covered by unemployment insurance display both a reduced wage growth and an increased wage volatility. The implication of these findings is that wage policies within firms should be flexible and performance-related in order to counter the disincentives coming from unemployment insurance. 


\section{Introduction}

The Danish "flexicurity" system has often been put forward as a solution to the problems of unemployment and labour market rigidity characterising Continental Europe. As is well known, in essence the system consists of generous unemployment insurance (UI) coupled with the absence of firing restrictions. Therefore, firms are free to manage labour demand, while an extended social safety net eliminates poverty risk and preserves social cohesion. Increasing labour market flexibility has been the goal of recent labour market reforms in Europe, for example in Italy and Spain. In these cases, flexibility has been achieved at the margin, e.g. by favouring the adoption of temporary employment for labour market entrants. While effective in reducing firing costs, such a strategy may increase income uncertainty to the extent that these contracts do not act as stepping stones into stable employment, inducing segmentation in the labour market. Flexicurity has been advocated in these countries as a way of reducing income insecurity and welfare losses associated with labour market reforms.

In this paper we look at the relationship between wage dynamics and individual membership of UI funds which represents the security part of the Danish flexicurity system. There is an extensive literature documenting the disincentive effects that UI may exert on job search and unemployment dynamics (see e.g. Lalive and Zweimuller, 2004). Other studies have shown that, by allowing longer search, UI may favour higher quality and longer lasting matches (Tatsiramos, 2009). There are also reasons to believe that UI may affect productivity and wage dynamics of the employed, for example through moral hazard (see e.g. Meghir and Pistaferri, 2011); however, the impact of UI schemes on wage dynamics is a somewhat underresearched topic and in this paper we contribute new evidence on this.

The objective of our paper is to answer the question: how do the wage dynamics of the insured compare to the uninsured? Hourly wages, rather than annual earnings or income, are the outcome of interest. To the extent that hourly wages reflect productivity they may be 
related to UI because of selection into insurance or moral hazard once insured. Earnings and income are also related to productivity, but involve additional behavioural responses and associated modelling challenges, as in Low et al. (2010) and Altonji et al. (2009), which are beyond the scope of the current paper.

We are the first to provide evidence on the relationship between UI and individual wage dynamics. We consider Danish men employed in the private sector during the period 19802003 and use population-based administrative data to distinguish between a life cycle wage profile and transitory wage shocks. We relate the two wage components to individual membership of UI schemes. Using time variation in membership status at the individual level, we are able to connect membership with changes in the inter-temporal covariance structure of wages. Our model is grounded in the well-established literature on permanent and transitory wage dynamics (Meghir and Pistaferri, 2011, Moffitt and Gottschalk, 2012).

A number of papers have studied the responsiveness of wages to UI. While these studies have all looked at the relation between UI and wage levels, none have considered wage dynamics, in particular the relation between UI and the covariance structure of wages, as we do in this paper. A first group of studies examines the relationship between unemployment insurance benefit replacement rates and reservation wages. A second group of studies analyses the incidence of unemployment insurance on wages via compensating differentials for unemployment risk, or via payroll tax burden shifting. Feldstein and Poterba (1984) use survey questions about reservation wages to show that the level of unemployment benefits relative to previous wages has a strong positive effect on reservation wages, and they argue this is due to the moral hazard cost of UI benefits. More recently, Shimer and Werning (2007) develop a theoretical model based around the argument that the net-of-tax reservation wage captures all relevant information about worker well-being. They derive the implications of this for optimal unemployment insurance. Topel (1984) estimates the effect of unemployment 
risk on wages, controlling for benefit levels as well as unemployment effects. He finds that the availability of UI reduces the size of compensating wage differentials (for unemployment) according to industry. Anderson (1994) extends the specification of Topel (1984) and finds compensating wage differentials for unemployment risk and that a decrease in benefits leads to an increase in wages. Anderson and Meyer (2000) analyse the incidence of payroll taxes (becoming experience-rated to unemployment) on wages. They find this tax is largely passed on to wages at the industry level.

Studies of consumption smoothing and partial self-insurance are also related to ours in a different way. Gruber (1997) models the consumption smoothing benefits of UI by estimating the relationship between consumption changes when becoming unemployed by level of UI generosity. Chetty (2008) extends this by identifying the effect of UI on relaxing liquidity constraints faced when unemployed. More generally, studies of partial self-insurance are concerned with the extent to which income processes map into consumption processes to reveal how well households are able to insure themselves, by one way or another. Blundell et.al. (2008) find that the change in degree of persistence of income shocks in the 1980's explains the observed greater increase in income inequality than in consumption inequality. There was a relative increase in the importance of insurable transitory shocks that are fully insured (consumption is smoothed) compared to permanent shocks that are only partly insured. Kaplan and Violante (2010) re-visit Blundell et.al. (2008) with a calibration model that does not allow consumption foresight and find somewhat lower permanent shock insurance. We do not have access to consumption data, but rather observe the take-up of a common form of insurance policy (UI), which is a direct (though partial) measure of the insurance these papers are inferring to.

We model the impact of UI fund membership on two key aspects of the individual wage process, life cycle wage growth and wage instability (i.e. transitory wage shocks). We find 
that UI affects both, reducing the heterogeneity of wage growth and increasing wage instability. We interpret these results as symptoms of moral hazard. Due to lower costs of separations for employees, UI may reduce the incentives to learn on-the-job and may increase shirking, translating into more compressed life cycle dynamics and more unstable employment and wage profiles. Our results also have implications for wage inequality, whose nature changes from persistent to volatile when individuals join the UI scheme. The maintained hypothesis for our interpretations is no selection into UI fund membership due to individual wage growth or wage instability. We cannot formally test moral hazard against selection, but we do perform a number of robustness checks whose results all support moral hazard effects rather than adverse selection.

Our interpretation of the results is in line with other findings in the literature. Burdett et al. (2011) study wage dynamics and inequality in a labour market characterised by on-the-job search and experience effects, finding that learning-by-doing increases wage dispersion. Prat (2010) estimates a Mortensen-Pissarides job search and matching model with learning-bydoing showing that the latter results in a positive effect of job tenure on wage dispersion, which is consistent with wage growth heterogeneity over job matches. In our context, by lowering the employee costs of job separations, UI may increase moral hazard, reducing effort and the associated learning-by-doing. The insured would thereby exhibit less wage growth heterogeneity than the uninsured if learning-by-doing is less important for them. In this way moral hazard would reduce the dispersion of wage growth rates. Furthermore, moral hazard may, in the limit, result in a job loss. Insured individuals should exhibit larger wage instability over their careers because of increased job separations and employment instability.

The remainder of the paper is organised as follows. Section 2 discusses the policy background for flexicurity in Denmark and the relevant literature. Section 3 surveys the relevant earnings literature and introduces our model of individual wage dynamics and UI 
membership. Section 4 describes the data and the estimation sample. Main results are presented in Section 5, while in Section 6 we subject them to robustness checks. Section 7 concludes.

\section{Institutional background}

Flexibility for employers to hire and fire workers and income security for the unemployed have both long been features of the Danish labour market. This was combined with effectively unlimited unemployment benefit duration until unemployment peaked in 1993. Thereafter introduction and tightening of time limits and activation (job search and training) requirements coincided with falls in registered unemployment until 2007. It is increasingly recognised that the triplet flexibility, income security and activation combined to facilitate low and stable registered unemployment in a Danish model of flexicurity (Andersen and Svarer, 2007). The remainder of this section details these salient features together with the wage setting context in motivation of our empirical work which contrasts wage dynamics across sub-populations differentially exposed to UI.

Employment protection in Denmark has been weak by international standards since the 1970's. ${ }^{1}$ Most blue-collar workers can be laid off with very short notice, the actual length of notice depending on the labour market agreement for the occupation and will usually depend on tenure in the job. Many white-collar workers and salaried employees are legally guaranteed a certain period of notice in case of layoffs according to their tenure in the position (one month notice for six months of employment, and an irregular step function up to a maximum of six months for nine years of employment). There is no similar law for bluecollar workers.

\footnotetext{
${ }^{1}$ For a general description of the Danish labour market, see Andersen et al. (2011).
} 
UI fund membership is open for anyone to join while in employment. Membership is voluntary and organised into different funds along occupation and industry lines by labour unions. ${ }^{2}$ UI funds have common contribution rates and benefits and are heavily subsidised through general taxation. Eligibility to benefits requires fund membership and employment for twelve months. In 2009 benefits were $90 \%$ of mean earnings over the previous three months subject to a maximum gross monthly payment of $€ 1,800$. The average production worker earning monthly $€ 3400$ faces a $52 \%$ gross replacement rate. Both earnings and transfers are taxed, but an $8 \%$ tax on labour earnings does not apply to unemployment benefits, which implies higher net replacement rates.

Social assistance is available to those without work who are uninsured or those for whom unemployment insurance eligibility has expired. The level of support varies according to family status, age and most importantly is means tested, but would typically be $70 \%$ of unemployment benefit levels. The means testing implies for example that an owner-occupier could not receive benefits.

Effective conditionality for unemployment benefit receipt was introduced in 1994. Previously passive receipt of benefits for up to nine years could be extended indefinitely by enrolment in training programmes. Activation in the form of mandatory training and job search came in after four years of unemployment, where the unemployed person is responsible for his own activation followed by three years where the UI system takes responsibility. Subsequently these time limits for the passive and active periods were reduced to $2+3$ (1996), $1+3$ (1998), 0+2 (2010). Activation for recipients of social assistance worked similarly in principle, but was not enforced until a recent reform which meant both groups were treated by the same authority.

\footnotetext{
${ }^{2}$ Neumann et al. (1991) and Clasen and Viebrock (2008) describe organisation, membership and coverage of labour unions and unemployment insurance funds. Although there is an overlap between UI fund membership and trade union membership, there is not a one to one relationship between the two, nor is there any formal link. Union membership is at a lower rate compared with UI fund membership: 70 percent versus 83 percent in 2003.
} 
Wage bargaining in the public sector has always been centralised and agreements are normally reached every second year. In the private sector wage bargaining was centralised until 1980. Industry-level bargaining was introduced in 1981 and by 1987 (2003) only 34\% $(15 \%)$ of wages were centrally bargained. Bargaining decentralisation became more and more widespread from 1993, when there was a maximum amount of firm-level bargaining at around $80 \%$. Since 1993 there has been a small element of individual negotiation that grew to $20 \%$ in 2000 .

In sum, the features of flexicurity most directly affect blue collar workers (by way of employment flexibility) and the low waged (income security with high replacement rates) post-1993 (by way of active labour market policies and reduced maximum benefit durations). Throughout the period there was a gradual decentralisation of wage bargaining, first to the industry level, post-1993 to the firm level and from 2003 to the individual.

\section{Modelling wage dynamics and UI fund membership}

How do the wage dynamics of the insured compare to the uninsured? To answer this question, in this section we develop an empirical model of individual wage dynamics and UI fund membership. First we provide an account of the earnings dynamics literature over the last two decades; next we present our model which introduces UI membership into individual wage dynamics.

\subsection{Related studies on wage and earnings dynamics}

Many economic models have been proposed in the literature to explain life cycle wage growth. Rubinstein and Weiss (2006) group these into three broad classes: search, asymmetric information and investment. Search models emphasise the role of limited information and labour market frictions in determining wages. Workers look for jobs, job offers are made, 
workers decide whether to accept the offers and wages change accordingly (Burdett, 1978). Asymmetric information models focus on limited information regarding worker productivity. Workers are different, their productivity is only revealed to the employer gradually on-the-job and wages change accordingly (Gibbons and Waldman, 1999). Investment models emphasize human capital accumulation in school and at work. Workers invest in on-the-job training, trade off reduced current for higher future wages and wages evolve accordingly (Mincer, 1974). Human capital may accumulate on-the-job not only through formal training activities, but also through production itself, by way of learning-by-doing.

Asymmetric information and search approaches emphasize within and between job wage growth respectively, while simple investment models focus on post-school human capital accumulation and life cycle wage dynamics. To compare individual wage dynamics of the insured and the uninsured, we estimate a simple life cycle wage model. By ignoring unemployment (assuming unobserved wages are missing at random) and employer identity (labour market experience is generic), we rule out distinguishing between search and asymmetric information approaches. Indeed, we will be interpreting our results referring to both within and between job dynamics. The only distinctive prediction we are able to test by assuming generic labour market experience comes from a simple Mincerian model of investment in human capital, which merits describing in more detail.

This Mincer model of human capital investment can account for important features of life cycle earnings. ${ }^{3}$ After completing formal schooling and joining the labour force, workers forgo some potential earnings for the sake of investment in on-the-job training. This lowers earnings early in the work career and increases earnings later as returns to post-school investments accumulate. In the absence of investment in training, potential earnings equal observed earnings at labour market entry. With post-school investment, there is an

\footnotetext{
${ }^{3}$ Surveys and extensions of the Mincerian earnings function approach are to be found in Heckman, Lochner, and Todd (2008) and Rubinstein and Weiss (2006).
} 
"overtaking point" at which observed and potential earnings are equal. One can think of this as a break-even point at which the earnings of investors and non-investors coincide. It is also termed the Mincerian cross-over because it is the point at which differently shaped earnings profiles intersect.

Obviously one needs to carefully model individual life cycle profiles in order to capture these phenomena, since observed earnings carry information about both long-term (or permanent) earnings and transitory fluctuations reflecting the unstable component of the earnings process, which may confound the estimation of earnings profiles. The distinction between two sources of income variation goes back at least to Friedman (1957) and empirically has been extensively investigated starting with the work of Lillard and Willis (1978), generating a large body of literature reviewed in Meghir and Pistaferri (2011).

A number of studies in that literature have formalised permanent wages or earnings over the life cycle as an individual-specific linear profile in age or experience, in which individualspecific intercepts measure human capital at labour market entry, whereas individual-specific slopes represent heterogeneity in human capital accumulation over time; a model that is typically referred to as a random growth model. Examples include Lillard and Weiss (1979), Hause (1980), Baker (1997), Haider (2001), Cappellari (2004) and Gladden and Taber (2009). In this model, the Mincerian trade-off between initial earnings and earnings growth translates into a negative covariance between individual-specific intercepts and slopes. Moreover, the assumption of linearity of individual wage growth implies that wage dispersion displays quadratic growth over the life cycle. In combination with Mincerian cross-overs, this results in a u-shaped pattern of wage dispersion over the life cycle, with wage differentials compressing up until the cross-over point, and fanning out afterwards. In this paper we will use a variant of this model to study life cycle wages and UI membership. 
Alternatively, studies of individual wage dynamics have been specifying the permanent wage as a random walk or unit root process, see e.g. Dickens (2000), Meghir and Pistaferri (2004) and Blundell et al. (2008). In this case, individual earnings evolve over the life cycle through the arrival of infinitely lived shocks, resulting in a linear trend of wage dispersion. Other studies such as Baker and Solon (2003) and Moffitt and Gottschalk (2012) have adopted specifications featuring both random growth and random walk components. Baker (1997) and Haider (2001) provide comparisons of the random growth and random walk approaches, concluding that the random growth specification provides a satisfactory characterisation of life cycle earnings dynamics.

\subsection{A model of wage dynamics and UI fund membership}

We model wage dynamics distinguishing between long-term or permanent wages and transitory fluctuations, and specify the former as a random growth process consistent with a Mincerian model. ${ }^{4}$ In principle both the permanent and transitory wage components may depend on UI membership, for example because it may affect effort and the associated learning-by-doing (permanent component) or job retention (transitory component reflecting employment stability). Therefore we allow UI membership to impact on both wage components.

We specify individual wages as:

$$
\begin{gathered}
y_{i c t}=m_{c t}+w_{i c t} ; i=1, \ldots, N ; t=t_{0 c}, \ldots, K_{c} ; \\
w_{i c t}=w_{i c t}^{P}+w_{i c t}^{T} ; E\left(w_{i c t}^{P}\right)=E\left(w_{i c t}^{T}\right)=E\left(w^{P}{ }_{i c t} w_{i c t}^{T}\right)=0
\end{gathered}
$$

where $y_{i c t}$ is the log- real wage in period $t$ for person $i$ who belongs to birth cohort $c$, and the time span of observation is cohort-specific. Individual log-wages depend on a period/cohortspecific mean $\left(m_{c t}\right)$ plus the individual deviation from it $\left(w_{i c t}\right)$. The latter is the sum of

\footnotetext{
${ }^{4}$ The random growth model is also consistent with the empirical patterns of life cycle wage dispersion in our data, see Figure 1 and the discussion in Section 4. As a sensitivity analysis on our specification, in Section 6 we will present estimates of a random walk model.
} 
permanent and transitory components, denoted with the $P$ and $T$ superscripts. Permanent and transitory wages are orthogonal by definition, which allows their identification. Allowing for the period/cohort-specific mean $m_{c t}$ is equivalent to including cohort-specific age dummies, which is crucial in our context since we are interested in individual life cycle profiles that may be confounded by cohort-specific wage growth. ${ }^{5}$

\subsubsection{Baseline model}

We start with a baseline model of wage dynamics which serves as a benchmark for our results; next we extend this specification to account for the role of UI. We specify long-term wages as random growth model, i.e. an individual-specific linear profile in potential labour market experience $E X P_{i t}$, the latter being defined as total time since first entering the labour market:

$$
w_{i c t}^{P}=\pi_{i} \lambda_{c}\left(\alpha_{i}+\beta_{i} E X P_{i t}\right) ; \quad\left(\alpha_{i}, \beta_{i}\right) \sim\left[(0,0) ;\left(\sigma_{\alpha}^{2}, \sigma_{\beta}^{2}, \sigma_{\alpha \beta}\right)\right]
$$

According to this specification, each individual's permanent wage is characterised by a starting level $\left(\alpha_{i}\right)$ and a growth rate $\left(\beta_{i}\right)$ drawn from a zero mean distribution. The variances of individual-specific parameters $\left(\sigma_{\alpha}^{2}\right.$ and $\left.\sigma_{\beta}^{2}\right)$ capture the degree of heterogeneity along these two dimensions, say due to initial ability and ability to accumulate productive skills once in the labour market. The covariance term $\left(\sigma_{\alpha \beta}\right)$ is also relevant. As discussed above, a negative covariance indicates the existence of Mincerian cross-overs (Hause, 1980). Alternatively a positive covariance suggests that those with higher schooling learn faster onthe-job. Depending upon the sign of this parameter, wage inequality will first decrease and then increase over the life cycle ( $\sigma_{\alpha \beta}$ negative), or it will increase continuously ( $\sigma_{\alpha \beta}$ positive).

\footnotetext{
${ }^{5}$ This "de-meaning" strategy was first introduced by Baker and Solon (2003), who noted that it is a flexible way to control for age effects. Other papers in the literature have been using first stage regressions that include in the right hand side polynomials in age, cohort effects and other individual characteristics (see e.g. Meghir and Pistaferri, 2004, and Moffitt and Gottschalk, 2012). Using time-varying fourth order polynomials in age in place of cohort-specific year dummies in the first stage regression produced results very close to the ones presented in the paper. Later in the paper we will show that including additional observables such as industry, education and the local unemployment rate in the first stage regression does not affect the results of the analysis.
} 
The random growth represents the core of our permanent wage specification and accounts for individual heterogeneity. In addition, we allow permanent wages to flexibly vary over calendar time and birth cohorts through a set of factor loadings $\pi_{t}$ and $\lambda_{c}$. In this way we ensure that estimation of core parameters is not confounded by variation occurring between cohorts and time periods, the sequence of labour market reforms discussed in the previous section being an example of the latter. ${ }^{6}$ Assuming independence between potential labour market experience and random growth parameters, the permanent wage auto-covariance implied by this model can be written as:

$$
\operatorname{Cov}\left(w_{i c t}^{P} w_{i c s}^{P} \mid E X P_{i}\right)=\left[\sigma_{\alpha}^{2}+\sigma_{\beta}^{2} E X P_{i t} E X P_{i s}+\sigma_{\alpha \beta}\left(E X P_{i t}+E X P_{i s}\right)\right] \pi_{t} \pi_{s} \lambda_{c}^{2}
$$

where $E X P_{i}$ is the vector collecting individual observations of potential labour market experience. $^{7}$

For the transitory wage model, in line with previous studies we adopt a low order ARMA process, in order to capture the fact that shocks to wages do not fade away instantaneously, but only after a few time periods. In particular, here we adopt an AR(1). ${ }^{8}$ In addition, as we did for permanent wages, we allow for flexible time and cohort specificshifters also in the transitory wage. Finally, as discussed by MaCurdy (1982), we treat the process as non-stationary and explicitly model the variance of its initial condition, i.e. the first period of observation. The initial condition is cohort-specific because generally cohorts are

\footnotetext{
${ }^{6}$ Time and cohort effects in permanent and transitory wages feature in many papers in the literature, such as Moffitt and Gottschalk (2012), Baker and Solon (2003), Haider (2001) and Dickens (2000). All these papers estimate models using log wage levels. Other studies such as Meghir and Pistaferri (2004) and Alvarez et al. (2010) estimating models of wage changes control for time and cohort effects in mean wages via first stage regressions, but do not allow for them in the permanent and transitory components of deviations from the mean, since the period shifters complicate identification of core parameters from the empirical autocovariance of first differenced wages.

7 As discussed in Gladden and Taber (2009), the assumption of independence between random growth parameters and labour market experience, which is ubiquitous in the literature, fails if actual experience (i.e. time actually spent working since entering the labour market) is used in place of potential experience due to endogenous intermittency of labour force participation.

${ }^{8}$ We also experimented with $\operatorname{ARMA}(1,1)$ specifications, but encountered convergence issues which suggests lack of identification of the MA component in our data. See Baker and Solon (2003) for similar remarks.
} 
first observed in different years, and cohort effects in its variance (as well as in the remaining $\mathrm{AR}(1)$ parameters) are captured by the cohort shifter $\mu_{c}$. In sum:

$$
w_{i c t}^{T}=\tau_{t} \mu_{c} v_{i t} ; \quad v_{i t}=\rho v_{i t-1}+\varepsilon_{i t} ; \quad \varepsilon_{i t} \sim\left(0 ; \sigma_{\varepsilon}^{2}\right) ; \quad v_{i t 0 c} \sim\left(0 ; \sigma_{0}^{2}\right) .
$$

Wage instability is captured by the variance of innovations, $\sigma_{\varepsilon}^{2}$. The $\operatorname{AR}(1)$ parameters and the cohort and period shifters are the argument for the auto-covariance function of transitory wages:

$$
\operatorname{Cov}\left(w^{T}{ }_{i c t} w_{i c s}^{T}\right)=\left\{d_{0 c} \sigma_{0}^{2}+d_{d c}\left[\sigma_{\varepsilon}^{2}+\operatorname{Var}\left(v_{i t-1}\right) \rho^{2}\right]+d_{l}\left[\operatorname{Cov}\left(v_{i t-1} v_{i s}\right) \rho\right]\right\} \tau_{t} \tau_{s} \mu_{c}^{2}
$$

where $d_{0 c}$ is a dummy for variances in the first year of observation, $d_{d c}$ is a dummy for variances in subsequent years and $d_{1}$ is a dummy for covariances. The orthogonality assumption in (1) implies that the total wage auto-covariance results from the sum of (3) and (5).

\subsubsection{Model with UI fund membership}

We now extend the baseline model to allow for individual membership of a UI fund in each wage component. As discussed in the previous section, membership is voluntary and individuals may change membership status, which generates time variation in membership at the individual level. Also, we know that typically labour market entrants are not insured and they first join the UI scheme only a few years after the beginning of their careers (see Ibsen and Westergård-Nielsen, 2008, and the data description in the next section). We therefore augment the random growth model by allowing the wage process to change after labour market entry, while leaving entry wages unaltered. We do so by introducing an interaction term between UI membership and individual wage growth. ${ }^{9}$ Let $F_{i t}$ be a dummy indicator for whether individual $i$ is a UI fund member in year $t$. Our extended random growth model is:

\footnotetext{
${ }^{9}$ By assuming that UI membership does not affect permanent wages through individual intercept terms but only through growth rates we are excluding the possibility of benefit pass-through effects via starting wages (see e.g. Currie and Madrian, 1999). To check the sensitivity of our results to this assumption, we estimated a version of
} 


$$
w_{i c t}^{P}=\lambda_{c} \pi_{t}\left(\alpha_{i}+\beta_{i} E X P_{i t}+\delta_{i} F_{i t} E X P_{i t}\right) ;\left(\alpha_{i}, \beta_{i} \delta_{i}\right) \sim\left[(0,0,0) ;\left(\sigma_{\alpha}^{2}, \sigma_{\beta}^{2}, \sigma_{\delta}^{2}, \sigma_{\alpha \beta}, \sigma_{\beta \delta}\right)\right]
$$

The additional individual-specific parameter $\delta_{i}$ measures the change in the slope of the individual experience profile associated with membership of a UI fund and its second moments provide information on the degree of heterogeneity in slope differentials $\left(\sigma_{\delta}^{2}\right)$ and their covariance with baseline slopes $\left(\sigma_{\beta \delta}\right)$. The sign of $\sigma_{\beta \delta}$ indicates whether the wage growth of fast tracks (high $\beta$ ) accelerates (high $\delta, \sigma_{\beta \delta}$ positive) or slows down (low $\delta, \sigma_{\beta \delta}$ negative) with membership. ${ }^{10}$

Assuming independence between the membership dummy and the vector $\left(\alpha_{i}, \beta_{i} \delta_{i}\right)$, the inter-temporal covariance structure for permanent wages becomes:

$$
\begin{aligned}
\operatorname{Cov}\left(w^{P}{ }_{i c t} w_{i c s}^{P} E X P_{i} F_{i}\right)= & {\left[\sigma_{\alpha}^{2}+\sigma_{\beta}^{2} E X P_{i t} E X P_{i s}+\sigma_{\alpha \beta}\left(E X P_{i t}+E X P_{i s}\right)+\right.} \\
& \sigma_{\delta}^{2} F_{i t} E X P_{i t} F_{i s} E X P_{i s}+ \\
& \left.\sigma_{\beta \delta}\left(F_{i t} E X P_{i t} E X P_{i s}+F_{i s} E X P_{i s} E X P_{i t}\right)\right] \pi_{t} \pi_{s} \lambda_{c}^{2}
\end{aligned}
$$

where $F_{i}$ is the vector collecting individual observations of UI fund membership.

Several points need to be made about identification of the additional parameters. First, identification requires individual level variation in UI fund membership over time, which is something that is present in our data as we document in the data section. Second, we are not assuming independence of membership and potential experience, which would contradict the empirical observation that it takes some time in the labour market before individuals become members; rather, we exploit the correlation between the two variables for estimating the extra parameters. Third, the assumption of independence between individual specific parameters and the membership dummy rules out the possibility of selection into membership. While we

\footnotetext{
the model in which both intercepts and slopes of the individual permanent wage profile were interacted with the UI membership dummy, and used log-wage residuals from a first stage regression that included the UI membership dummy alongside $m_{c t}$, plus their interaction, in the right hand side. Results of this sensitivity analysis were entirely in line with those presented here and are available upon request.

${ }^{10}$ Although the covariance between intercepts and slope shifters is in principle also identifiable, we restrict it to zero in order to ease interpretation and not to overcrowd the parameter space. While robustness checks with more extended parameterisations led to results in line with the ones presented in the text, the parameters specified in (6) are enough to fully characterise the variation of the wage profile associated with UI.
} 
cannot directly test for it, in Section 6 we provide several robustness checks indicating that our results are not driven by selection.

To characterise the link between wage instability and UI fund membership, we need to take a different approach to the one followed with the permanent wage, given that the instability parameter $\sigma_{\varepsilon}^{2}$, although conceptually defined at the individual level, has no individual-specific empirical counterparts. ${ }^{11}$ Baker and Solon (2003) studied the relationship between instability and age by exploiting variation over cohorts and time periods and by specifying the variance of $\mathrm{AR}(1)$ innovations as a function of the average age of a cohort over time. Here we take an approach similar in spirit to theirs and parameterise the variance of innovations as a function of the average UI membership across cohorts and years, $F_{c t}$ :

$$
\sigma_{\varepsilon c t}^{2}=\sigma_{\varepsilon}^{2} \exp \left(\psi F_{c t}\right)
$$

Since the incidence of UI membership varies across cohorts and time, the resulting instability parameter on the left hand side of (8) varies with $c$ and $t$, which identifies $\psi$. A positive estimate of $\psi$ would indicate a positive association between wage instability and UI membership. Note that cohort and time trends in the transitory wage are already flexibly controlled for by the factor loadings $\tau_{t}$ and $\mu_{c}$, so that $\psi$ will not capture variation in instability over cohorts and time, but rather the effect of UI on instability in a difference-in-differences setup. Substituting $\sigma_{\varepsilon}^{2}$ in (5) with $\sigma_{\varepsilon c t}^{2}$ yields the theoretical transitory wage auto-covariance function that we use in the analysis. Adding it to (7) provides the total wage auto-covariance function that accounts for UI fund membership, which we denote $\Omega\left(\theta, X_{i}\right)$, where $\theta$ is the parameter vector that contains random growth terms, AR parameters and the shifters for periods and cohorts on each wage component, while $X_{i}$ is the union of $E X P_{i}$ and $F_{i}$.

\footnotetext{
11 Assuming that permanent wages are time-invariant, it is possible to derive an individual-specific approximation of the instability parameter $\sigma_{\varepsilon}^{2}$ following the approach of Gottschalk and Moffitt (1994). Later in the paper we will provide some evidence using this alternative approach.
} 
We estimate $\theta$ by Minimum Distance (see Chamberlain, 1984; Haider, 2001). ${ }^{12}$ This is an application of the GMM: the inter-temporal auto-covariance function of wages implied by the specified model is mapped into empirical second moments of the within-cohort intertemporal distribution of residual log-wages $A_{c}=N_{c}^{-1} \Sigma_{i \in c} A_{i}, A_{i}$ being the individual contribution to $A_{c}$ and $N_{c}$ the size of cohort $c$. We form $A_{i}$ using the variances and covariances of the empirical counterparts of $w_{i c t}$, obtained from cohort-specific regressions of log-wages on time dummies. Let $a_{i}=v e c h\left(A_{i}\right)$, and $\omega\left(\theta, X_{i}\right)=\operatorname{vech}\left[\Omega\left(\theta, X_{i}\right)\right]$. The parameter vector is identified by the following set of moment restrictions:

$$
E\left[a_{i}-\omega\left(\theta, X_{i}\right)\right]=0
$$

Following previous studies such as Dickens (2000), Haider (2001), Baker and Solon (2003) and Moffitt and Gottschalk (2012), we estimate the parameters from the empirical autocovariance structure of levels of log-wage residuals.

\section{Data and descriptive statistics}

We use administrative register data for the Danish labour force between 1980 and 2003. We consider men only, in common with the literature on wage components models, with the aim of excluding the more intermittent labour force participation of women which would otherwise inflate wage instability. Similarly, we exclude very young workers and workers approaching retirement and consider prime age men aged 21-55. We focus on full-time private sector employees.

Our three main variables of interest are gross hourly wages, UI fund membership and potential labour market experience, all derived from administrative registers. Gross hourly wages are calculated by Statistics Denmark using annual labour earnings divided by hours

\footnotetext{
${ }^{12}$ We use Equally Weighted Minimum Distance (EWMD) and a robust variance estimator $\operatorname{Var}(\theta)=\left(G^{\prime} G\right)^{-}$ ${ }^{1} G^{\prime} V G\left(G^{\prime} G\right)^{-1}$, where $V$ is the fourth moments matrix and $G$ is the gradient matrix evaluated at the solution of the minimisation problem.
} 
worked. Individual annual labour earnings are reported by employers to the tax authorities. Hours of work were not registered directly over our sample period and were not available to us. Statistics Denmark derived the hours information used in the calculation of wage rates from several different sources which produce an annual average measure. ${ }^{13}$ UI fund membership contributions are tax-deductible and reported to the tax authorities on an annual basis by the funds. Potential experience is calculated as years since entering the labour market. We observe year of labour market entry by way of mandatory pension contributions which were first introduced in 1964. Information on the year of labour market entry is censored at 1964 for those who started working before that date.

We estimate the parameters of interest by exploiting variation across cohorts and time of the within-cohort wage autocovariance structure; it is therefore important to define sample selection also according to the year of birth. In order to have a sufficiently long period of observations by cohort, we require that each cohort is observed for at least ten years. The youngest birth cohort in our sample is the one that turns 21 (and thus meets the selection criteria on age) in 1994 (and thus is observed at least ten years before the sample period ends), i.e. the birth cohort of 1973 . In principle, we could reason symmetrically at the other end of the sample period and use as the oldest group men that turn 55 in 1989 (thus being observed for at least ten years after the beginning of the sample period), i.e. the birth cohort of 1934 . However, due to the above mentioned censoring of labour market entry before 1964, which is necessary to define potential experience, we could not use cohorts whose career began before 1964, and used as oldest cohort the group turning 21 in 1964, i.e. individuals born in 1943. In sum, we use information on men born between 1943 and 1973, and we group them into 31 single-year birth cohorts.

\footnotetext{
${ }^{13}$ The basis of the hours calculation is mandatory pension contributions which are made according to various concepts of hours worked or availability for work. These are adjusted for different rates of contribution by sector and collective agreement over time which differentially cover work, unemployment, sickness and various leave schemes.
} 
We allow individuals in these cohorts to enter and exit the panel according to the specified age criteria and do not consider their wage observations falling outside this age range, inducing a rotating panel design by cohort (see Baker and Solon, 2003). Cohorts born between 1943 and 1947 reach the age of 55 before the end of the sample period and therefore stop contributing between 1999 and 2003. Intermediate cohorts (born between 1948 and 1959) belong to the 21-55 age range throughout the sample period. Finally cohorts born from 1960 onwards turn 21 after 1980, and therefore start contributing to estimation after the beginning of the sample period. The unbalanced-by-cohort design provides identification of time and cohort effects.

The last sample selections are related to the hourly wage variable. First we drop cases of employed individuals for which the wage is recorded as zero. Secondly, to limit the influence of outliers we drop the lower and upper 0.5 percent of the resulting wage distribution for each year. ${ }^{14}$ Next we further exclude (the remaining few) wage observations falling below the minimum wage. Finally, for each individual, we require valid wage observations for at least five consecutive years to ease the identification of individual wage profiles. ${ }^{15}$ The latter restriction implies that our panel is not fully unbalanced, thus mitigating the issues reported by Haider (2001) with fully unbalanced designs.

\section{$<$ TABLE $1>$}

Descriptive statistics for our sample are presented in Table 1. The estimating sample consists of roughly 810,000 individuals for a total of about 12.5 million person-year observations. The incidence of UI membership is above 80 percent in each year and follows a hump-shaped profile through the sample period, peaking at 95 percent in the mid-1990s and

\footnotetext{
${ }^{14}$ We experimented with alternative trimming rules (i.e. no trimming and 1 percent trimming) and found that results were not affected.

${ }^{15}$ This latter sample selection rule is intermediate between the one used by Baker and Solon (2003), i.e. continuous earnings strings for each individual, and the approach of Haider (2001), who allows individuals to move in and out of the sample with the only requirement of having two positive but not necessarily consecutive valid observations on earnings. As robustness checks, we also estimated the main model requiring alternatively two or ten consecutive wage observations per worker. Our findings, discussed in the next section, were unaffected by the use of these alternative samples.
} 
then falling to 89 percent in the latest years; this pattern reflects the revolving-by-cohort design of the sample and the fact that the young have lower UI membership than older individuals (see the description of UI membership later in this section). The table also reports statistics on the wage distribution, both for the whole sample and by UI status. There is real wage growth and increasing dispersion. Average hourly wages increase by 28 percent between 1980 and 2003, an average yearly growth rate of 2.2 percent. Wage levels and growth are lower among UI members than among non-members. The wage distribution of UI members is also more compressed and displays a more limited increase of inequality relative to non-members. Subsequent rows tabulate average potential labour market experience. Average experience grows by approximately 12 years over the 23 years of the sample. Experience growth over time is more pronounced for UI members than for non-members, which reflects the fact that labour market entrants joining the sample through the years are typically non-members.

Both wage dispersion and experience grow over the sample period. Considering that the econometric model specified in Section 3.2 predicts that wage dispersion grows with the accumulation of experience, the increasing wage dispersion singled out in Table 1 may not necessarily reflect secular trends but rather be a symptom of the increasing experience. We isolate time trends in wage dispersion in the last rows of the table, which report wage dispersion over time for groups of fixed labour market experience, 10 and 20 years, distinguishing members and non-members of UI schemes. There is strong evidence of growth over time in within-group wage dispersion.

\section{$<$ TABLE 2>}

Table 1 indicates substantial differences in the wage distribution between members and non-members of UI schemes and shows that on average members are in the vast majority. In Table 2 we provide a closer look at the characteristics of members by tabulating UI incidence, 
UI entry rates (defined as proportion of non-members joining the scheme between one year and the next) and UI exit rates (proportion of members leaving the scheme) against demographic (age, potential experience, education) and job (occupation, industry) characteristics. We also break down UI transition rates by phase of the business cycle, separating falling unemployment years (1984-1986 and 1994-2003) from those with rising unemployment (1980-1983 and 1988-1993). The first column tabulates UI membership rates by personal characteristics, starting with age groups. Existing studies show that there is an age related element to UI fund membership, namely individuals join a few years after entry in the labour market, say in their late 20's or early 30's (see Ibsen and Westergård-Nielsen, 2008). Table 2 confirms that membership is relatively low at young ages (the table also reports figures for the 18-20 age group that is not included in the analysis sample) and grows rather steeply between 18 and 30. Life cycle patterns of UI membership are also evident when considering potential labour market experience, showing that UI membership is an exception at labour market entry and supporting our modelling approach in Section 3.2 of allowing for UI wage effects only after labour market entry. There are other evident associations of UI membership rates with individual characteristics, membership being larger among the less educated, manual workers (we have consistent information on occupations only until 1995, and statistics by occupation are computed restricting the sample to those years) and workers in manufacturing and construction. Low membership rates characterise service industries, especially financial services.

Remaining columns in Table 2 report UI entry and exit rates. Entry rates are the highest before age of 25 , over the first five years in the labour market and in industries with high incidence. Life cycle patterns are also evident in exit rates, which are higher at young ages and at low levels of potential experience, indicating that membership is more volatile for the young compared with older groups. The breakdown by phase of the business cycle shows, as 
could be expected a priori, that individuals join the UI scheme frequently during downturns, while exits from the scheme are more common in years of declining unemployment.

Overall, the evidence from Table 2 reveals that workers' selection into UI membership is associated with individual and job characteristics, displays life cycle patterns and is influenced by the business cycle. All of these factors will be taken into account in the econometric analysis of the next sections.

\section{$<$ FIGURE 1>}

As a last piece of descriptive evidence, in Figure 1 we present the covariance structure of log-wage residuals (log-wages "de-meaned" by time and cohort effects as in (1)), i.e. the empirical second moments of the inter-temporal wage distribution that are to be analysed by means of the model presented in Section 3.2. The figure displays trends in the residual wage variance and covariances. The latter are computed over time intervals of increasing width (1, 5, 10 and 15 years); the longer interval width, the greater the extent to which covariances approximate the variance of permanent wages, as the persistence of transitory shocks fades away over lags. While the second moments to be used in estimation vary over cohorts, in Figure 1 we abstract from cohort-wise variation and report figures averaged across cohorts. The left panel of Figure 1 plots the wage variance and covariances over time. The figure reproduces the upward time trends of wage dispersion observed in Table 1. Upward trends also characterise wage covariances, but those in "long" covariances appear less pronounced than the ones in the variance. Since the latter contains both permanent and transitory shocks, the evidence suggests that the variance of transitory wages may be increasing towards the later years of the sample. The right panel of Figure 1 repeats the exercise with trends in potential labour market experience. All series are trending upwards, showing that there is marked variation over the life cycle; moreover, the steepness is very similar between variance and "long" covariances, suggesting that life cycle effects are concentrated in the permanent 
component and pointing towards the appropriateness of permanent wage models that allow for life cycle effects. Another remarkable feature in the left panel is the wage compression characterising the experience profile over the first five years, followed afterwards by widening wage differentials. As discussed in Section 3.1, this pattern of wage dispersion, which is also visible in the wage covariances, is a distinctive feature of the random growth model, and is generated by the Mincerian cross-over of individual wage profiles. Random walk models, while also allowing for life cycle effects in wage dispersion would not be capable of capturing the compression/decompression effect because they assume linear life cycle trends of wage dispersion.

\section{Results}

Before discussing the central results about UI and life cycle wage dynamics, it is instructive to consider model predictions in Figure 2. The figure is generated using parameter estimates from the baseline model to predict variance components, which are then averaged across cohorts. Comparing the series of predicted total variance in Figure 2 with their actual counterparts in Figure 1 provides insights on the ability of the model to fit the data.

\section{$<$ FIGURE 2>}

The left panel of Figure 2 plots the predicted variance of wages and its permanent and transitory components over time. The predicted total variance increases over the period reproducing the evidence from Figure 1, with the patterns of predicted total variance mimicking almost identically actual ones, which may not be surprising given the presence of flexible shifters by cohort and time on each wage component. The variance decomposition reveals that permanent wage inequality is the main driver of increasing dispersion. Wage instability, on the other hand, is generally constant, except for the end of the period, when it increases sharply. The time patterns of permanent inequality are consistent with the presence 
of experience-related wage growth in the permanent component and the fact that average experience grows over time. These effects are illustrated in the right panel of Figure 2, which describes trends over potential experience. Again we can see that the profile of total variance reproduces quite closely its counterpart in Figure 1. While permanent variance grows with experience, transitory variance shows the opposite pattern, consistent with the idea that more experienced men enjoy more stable careers compared with less experienced workers.

\section{$<$ TABLE 3>}

\subsection{Baseline model}

In Table 3 we report the core parameter estimates for the wage models of Section 3.2, while the full set of estimated time and birth cohort shifters on the two wage components is reported in the Appendix Tables. ${ }^{16}$ We start by describing results for the baseline model, i.e. the model which does not allow for an impact of UI on the wage components. These estimates are presented in the first column of Table 3.

Estimated parameters of the permanent component indicate the existence of significant heterogeneity in both starting wages $\left(\sigma_{\alpha}^{2}\right)$ and wage growth rates $\left(\sigma_{\beta}^{2}\right)$. The estimates imply that someone located one standard deviation above the mean in the distribution of wage growth rates sees his wage growing 2.8 percentage points faster than the mean $\left(=\sqrt{\hat{\sigma}_{\beta}^{2}}\right.$, a hat denoting estimated coefficients). Considering that the average annual growth (estimated in a separate regression of $\log$ wages on a linear experience trend) was 0.9 percent, these results indicate that growth rate heterogeneity is substantial; the result is also very close to the one reported by Baker (1997) using the Panel Study of Income Dynamics. The two sources of heterogeneity are negatively correlated $\left(\hat{\sigma}_{\alpha \beta}<0\right)$ : individuals who enter the labour market

\footnotetext{
${ }^{16}$ Models with unrestricted loading factors produced negative and insignificant estimates of the permanent wage loading factors for the two youngest cohorts. To overcome this issue, we constrained permanent wage loading factors to be the same on the five youngest cohorts. Core parameter estimates were very similar in the constrained and unconstrained models.
} 
with high wages also experience the slowest growth over the life cycle, and vice-versa. The result is common to many studies in the literature: see Hause (1980), Baker (1997), Haider (2001), Baker and Solon (2003), Gladden and Taber (2009). The leading interpretation for this finding is that it reflects the trade-off between initial earnings and earnings growth as predicted by the Mincer model. The trade-off implies that the wage profiles of persons with different levels of initial wages intersect after some years in the labour market, see the discussion in Section 3.1. Consequently, long-term inequality first decreases and then increases over the life cycle, increases taking place after the cross-over. Hause (1980) computes the cross-over point $t^{*}$ as the year in which permanent inequality is at its minimum: $t^{*}=-\sigma_{\alpha \beta} / \sigma_{\beta \cdot}^{2}{ }^{17}$ Our estimate of the cross-over from this baseline model is at 4.25 years of potential labour market experience (s.e.=0.15), approximately one year later than the estimate obtained by Hause in a sample of Swedish men in the 1960s.

Consider now the transitory wage of the baseline specification. All core parameters are precisely estimated. The autoregressive coefficient indicates the weight that lagged transitory shocks have in current shocks, the weight being given by the coefficient exponentiated using the lag. The estimate of $\rho(=0.77)$ implies that after ten years the weight of lagged shocks in current shocks is negligible (5 percent). Note also that the variance of initial conditions $\left(\sigma_{0}^{2}\right)$ is precisely estimated. Given that our data spans a much longer time interval than the one required for past shocks to fade away, the significant estimate of initial conditions variance is unlikely to reflect a short panel issue but, rather, illustrates the relevance of treating the process as non-stationary by explicitly modelling its initial conditions.

\footnotetext{
${ }^{17}$ Note that this is also the negative of the regression coefficient of intercepts on slopes.
} 


\subsection{Model with UI fund membership}

The second column of Table 3 presents estimated parameters for permanent and transitory wages in the model with UI fund membership. As discussed in Section 3.2, the model is estimated under the assumption of no selection into UI. This is important for interpretation of the results and will be subject to robustness checks in the next section.

There is a substantial difference in wage growth between members and non-members of UI funds, the estimated variance of wage growth differentials $\sigma_{\delta}^{2}$ being statistically significant and of a size that is comparable with the baseline parameter $\sigma_{\beta}^{2}$. Taken in isolation this coefficient is not informative on whether UI is associated with more or less growth heterogeneity. Making statements about the way wage profiles change when individuals are members of UI funds requires taking into account the estimated covariances between baseline parameters and slope shifters. The covariance between baseline slopes and slope shifters $\left(\sigma_{\beta \delta}\right)$ is statistically significant and negative, indicating that UI fund membership is associated with compression of the distribution of wage growth, which would occur if e.g. fast tracks slow down on joining a UI fund. The estimates imply that someone located one standard deviation above the mean in the distribution of wage growth rates sees his wage growing 3.1 percent (= $\sqrt{\hat{\sigma}_{\beta}^{2}+\hat{\sigma}_{\delta}^{2}+2 \hat{\sigma}_{\beta \delta}}$ ) faster than the mean if he is a member, or 3.4 percent faster for a nonmember $\left(=\sqrt{\hat{\sigma}_{\beta}^{2}}\right)$. Consequently, as labour market experience accumulates, permanent inequality becomes greater among non-members than members. Also, the more homogeneous wage profiles of members result in delay of Mincerian cross-overs, for members compared with non-members, 3.4 versus 4.2 years of labour market experience, respectively. ${ }^{18}$

Consider now the transitory wage in the main model. Comparing these results with those from the baseline model shows that parameter estimates are rather stable. The one

\footnotetext{
${ }^{18}$ Note that the computed cross-over point is a non-linear function of estimated parameters so that the point computed in the baseline model does not need to belong to the interval defined by the equivalent points for members and non-members in the model with UI membership.
} 
parameter whose estimate differs across models is the variance of $\operatorname{AR}(1)$ innovations $\left(\sigma_{\varepsilon}^{2}\right)$, and the reason is that in the baseline case the parameter measures average (across levels of UI membership) instability, whereas in the second it measures instability for the (hypothetical) case of no UI membership. The additional parameter $\psi$ measures the instability shift associated with UI fund membership. The positive estimate indicates that UI fund membership corresponds to more wage instability. Parameter estimates imply that a high level of UI membership (above the ninetieth percentile of its distribution across cohorts and time) corresponds to a 25 percent increase of wage instability compared with the sample mean instability. $^{19}$

\section{$<$ FIGURE 3>}

We use estimates of the random growth parameters, the AR(1) parameters and the factor loadings on time and cohorts to predict inequality in the two wage components for members and non-members of UI over the life cycle. For each birth cohort we use parameter estimates to predict variance components, and then average predictions over cohorts. Results are presented in Figure 3. The graph in the left panel shows that UI membership is associated with lower permanent inequality throughout the life cycle, with the gap between nonmembers and members widening with potential labour market experience. This reflects the larger dispersion of wage growth rates found among non-members. Transitory inequality follows the opposite pattern, as seen in the right panel of the figure. There is a decline of earnings instability with experience for both members and non-members, reflecting the lower volatility of older cohorts. Differences between members and non-members are striking. For

\footnotetext{
${ }^{19}$ We experimented estimating the effect of UI on wage instability using the approach of Gottschalk and Moffitt (1994) referred to in footnote 11 . We regressed the approximate instability measure on a UI dummy (controlling for time, age, experience, industry and local unemployment) using fixed effects estimators. We found a positive and significant effect of UI on instability, although of limited size: the implied shift of instability due to UI was 1 percent of the sample mean instability. The much more limited impact of UI in the approximate instability measure compared with the model-based one could reflect the fact that by assuming time-invariant permanent wages, the approximate measure may pick up permanent wage dynamics (Shin and Solon, 2011), where UI effects are the opposite.
} 
non-members the decline is smooth and almost complete within the first fifteen years of labour market experience. For members, the life cycle decline is slower (actually there is a slight increase over initial years) and there is no tendency for instability to disappear even for high levels of labour market experience. Overall, Figure 3 illustrates that membership of UI funds is associated with a shift in the nature of wage differentials, from permanent to transitory.

\subsection{Discussion}

These results show that while permanent inequality is lower for UI fund members because of more compressed returns to experience, their wage instability is larger than that of nonmembers. Moral hazard effects can explain both results. Being insured may weaken the incentives to care about the good which is insured, in this case being employed. Insured workers may for example lose incentives to exert effort and to learn new productive skills onthe-job. In a model with on-the-job search and experience effects, Burdett et al. (2011) show that learning-by-doing increases wage dispersion. Prat (2010) shows that learning-by-doing results in a positive effect of job tenure on wage dispersion, which is consistent with wage growth heterogeneity over job matches. In our context, by lowering the employee costs of separations, UI may increase moral hazard and reduce workers' effort and the associated learning-by-doing, in turn reducing heterogeneity in wage growth. Moral hazard may, in the limit, result in a job loss. This would make work histories more unstable and generate the greater wage instability of UI members that we observe. According to this interpretation, UI has a causal effect on the wage process, and changes the nature of wage inequality from permanent to transitory. ${ }^{20}$

\footnotetext{
${ }^{20}$ The text highlights a direct effect of UI on wage growth dispersion through reduced incentives to learning-bydoing. A more indirect effect, of the same sign of the one discussed, may work through increased job separations and the associated depreciation of human capital. We assessed the relevance of this indirect effects for our findings by estimating the model on samples where human capital depreciation induced by job separations was
} 
Clearly, the validity of moral hazard interpretations requires that the identification assumptions introduced in Section 3.2 hold. First we have assumed independence between UI fund membership and individual-specific wage growth differentials, which enabled us to derive the moment restrictions for permanent wages in the model with UI fund membership, see equation (7). Second, we have assumed that differences in wage instability across cohorts and time periods are absorbed by the set of birth cohorts and calendar time shifters on transitory wages, so that we can use variation in the incidence of UI fund membership across cohort-period cells to estimate the association between UI and instability, which is the parameter $\psi$ in equation (8).

Selection into UI membership may lead to violation of the identification assumptions. The most obvious source of selection is heterogeneous risk aversion. Risk-averse workers may both join the UI scheme and be willing to trade wage growth for wage insurance through implicit contracts that insulate their labour incomes from shocks to profits; see Guiso et al. (2005) for a model of insurance provision within the firm. This would mean that there is an unobserved factor, risk aversion, affecting both UI membership and (indirectly through implicit contracts) wage growth, violating the assumption of independence between UI and individual-specific wage growth. Our results, however, do not support these mechanisms: while the reduction of wage growth heterogeneity for UI members is consistent with the implicit contract hypothesis, their larger wage instability does not square with firm provided insurance.

One can think of other examples of selection when there is heterogeneity in either wage growth or employment (and thereby wage) instability. For example, learning ability may be seen as a way to insure oneself against the risks of job loss. When workers reach the peak of

presumably lower, i.e. alternatively selecting more stable wage trajectories with at least ten years of continuous observations (rather than five as in the main text) or excluding wage observations following two or more years of absence from the sample. Results obtained from these alternative samples where entirely in line with those of Section 5.2, favouring the direct-effect interpretation of findings. 
learning capacity and their wage growth slows down, they may think of supplementing learning-based self insurance with fund-based insurance. Hence, it would not be the presence of UI that weakens wage growth, but rather the anticipation of a slowdown in wage progression that leads individuals to join the scheme, inducing reverse causation between wage growth and UI, violating the independence assumption of equation (7). Similarly, individuals with intrinsically low job attachment (and therefore highly volatile wage profiles) may join the insurance scheme more than workers with higher employment stability, inducing reverse causation between wage instability and UI. We assess the plausibility of these interpretations in the next section.

\section{Sensitivity analyses}

In this section we examine the sensitivity of our estimates by performing a number of robustness checks. In Section 4 we showed that there are certain personal attributes that are associated with UI membership, while the maintained assumption for our model is no selection into UI. The question in the present section is not whether selection into UI exists in general, but rather if such selection can be the driver of our results. To provide answers, first we look for evidence of selection into membership due to wage growth and wage volatility, i.e. the two sources of selection that may violate the maintained assumption of our model. Then we return to the wage dynamics model and conduct a number of checks on its specification and sample definition, all aimed at assessing the possibility that the results presented in Section 5 are driven by selection into UI. We start by estimating the wage process on UI switchers alone; next we assess overall model specification by adjusting for the main determinants of UI; then we focus on the specification of the permanent wage; and finally we consider the specification of the transitory wage. 


\subsection{Selection into UI by wage growth and instability}

If our findings were the result of selection effects, then we should observe a negative effect of lagged wage growth on UI fund membership, because individuals join a fund when wage growth slows down. We should also observe a positive relationship between lagged wage instability and membership, because individuals join a fund when their wage profiles become more volatile. We define wage growth as the log wage change between two consecutive years, and we estimate models in which individual membership indicators are regressed on lagged wage growth. We approximate wage instability using individual-specific measures of wage volatility along the lines of Gottschalk and Moffitt (1994). Assuming, as they do, that permanent wages are time-invariant, we derive transitory wages as the log-wage deviation from individual specific multi-year averages. We average wages over 5-year rolling windows and define wage volatility as the average of either squared or absolute deviations from the average. We regress UI membership indicators upon the lags of these volatility measures.

\section{$<$ TABLE 4>}

Results from our first robustness check are reported in Table 4. All models include controls for industry and local unemployment (i.e. the main determinants of UI fund membership) plus time and age trends. The outcome variable in these regressions is the individual sequence of UI fund membership, limiting the sample to cases in which individuals are observed joining the UI scheme. We focus on sequences in which individuals become members after a number of years of non-membership, and consider non-membership windows between 1 and 5 years. We used fixed effects regressions, either linear probability or logit models.

The first row of Table 4 reports results for lagged wage growth. The sign of the estimated coefficients is always positive, whereas they are statistically significant only in few cases, i.e. logit models with one or two years of prior non-membership and linear probability 
models with one year of prior non-membership. In all remaining cases, the effect of lagged growth on UI membership does not appear to be statistically significant at conventional confidence levels. None of the estimated effects is negative, as would be the case in the presence of selection into UI membership due to wage growth.

In the lower rows of the table we look at the relationship between UI membership and lagged wage volatility. In each of the cases considered the regression coefficient is negative and statistically significant, pointing towards a negative association between lagged volatility and the decision to join a UI fund. This is the opposite of what one would expect if selection into UI based on wage instability was driving our results. Taken together with the results on wage growth, these findings support our identifying assumptions of no selection into UI membership.

\subsection{Wage process for UI switchers}

As noted in Section 3.2, identification of UI membership parameters is achieved thanks to individual variation in membership over time. In our second robustness check we take a closer look at the characteristics of the wage process for these UI switchers, using the baseline model as a benchmark. In practice, we estimate the baseline model on the sample of individuals that change membership status over the sample period, representing just under 40 percent of the original sample (about 300,000 individuals). Our interest is in assessing how the parameters of the wage process estimated on this sample compare to the ones from the full sample reported in Table 3.

\section{$<$ TABLE 5>}

Results from this exercise are presented in the first column of Table 5. Core parameter estimates from the sample of UI switchers tend to align pretty closely with the ones obtained on the full sample. The most relevant difference between the two samples is the initial 
variance of permanent wages $\left(\sigma_{\alpha}^{2}\right)$, the corresponding coefficient estimate being much smaller in the sample of switchers compared with the full sample. Estimates of the coefficients most closely related to UI in the main model, (the dispersion of wage growth rates and the variance of transitory shocks) do not change dramatically between the two samples, suggesting that our main results on the impact of UI membership on wage growth heterogeneity and wage instability are not driven by the inherent characteristics of those who change membership status.

\subsection{Adjusting wages for the determinants of UI}

In Section 4 we showed that there is heterogeneity in UI membership according to individual characteristics. Our third robustness check takes this heterogeneity into account by adjusting individual earnings for the effects of the main determinants of UI. We do this by estimating our model on wage residuals derived from cohort-specific first stage regressions that include time dummies plus 2-digit industry dummies and industry-specific time trends, years of education and the local unemployment rate, both interacted with time dummies. The aim of this exercise is to remove, in a reduced form fashion, the effects of observed heterogeneity in UI determinants from raw wages before estimating wage second moments. If unobserved heterogeneity in UI is driving our results and if this heterogeneity is correlated with observed UI determinants, then estimates of the wage dynamics model with UI should be sensitive to the adjustment for UI determinants.

Results from this exercise are presented in the second column of Table 5. Comparing these with their counterparts in Table 3, it is evident that findings are robust to the adjustment for UI determinants. The general pattern of the estimates confirms the evidence in Table 3 , the main differences being a smaller instability effect of UI membership and a lower autoregressive coefficient, which may be the consequence of having removed some observed 
heterogeneity from log-wage levels. Overall, results from this exercise suggest that heterogeneity in the determinants of UI fund membership is not driving our main findings. ${ }^{21}$

\subsection{Independence of UI membership and parameters of the permanent wage}

Our sensitivity analysis continues by experimenting with alternative specifications of the permanent wage. We start by assessing the assumption of independence between UI membership and the parameters of the permanent wage component. We do this by substituting in equation (6) the individual UI membership indicator $F_{i t}$ with its aggregate counterpart $F_{c t}$, so that our model of permanent wages becomes:

$$
w^{P}{ }_{i c t}=\lambda_{c} \pi_{t}\left(\alpha_{i}+\beta_{i} E X P_{i t}+\delta_{i} F_{c t} E X P_{i t}\right) .
$$

With this specification, independence between UI membership and individual wage heterogeneity needs to hold only between cohort-period cells, while it is no longer required within those cells. Considering that the model already controls for between-cell heterogeneity through the set of time and cohort factors $\pi_{t}$ and $\lambda_{c}$, identification of $\sigma_{\delta}^{2}$ and $\sigma_{\beta \delta}$ will result from variation in wages and membership over cohorts and time in a difference-in-differences setup.

The results obtained using the specification in (6') for permanent wages are reported in the third column of Table 5. Parameter estimates are pretty much in line with their counterparts from Table 3, providing support for the assumption of no selection into UI membership. The most notable difference relates to the effect of membership on instability, the corresponding parameter $\psi$ being now lower, which is not surprising given that its estimation exploits the same variation over cohorts and periods that identifies permanent

\footnotetext{
${ }^{21}$ As a further general check on model specification and robustness of results, we experimented with excluding UI effects from the permanent or the transitory wage in turn, finding in both cases that the remaining UI effect was in line with the ones presented in Section 5. We also controlled model sensitivity to the exclusion of low or high UI membership industries (finance and construction, respectively), finding that results were robust to these exclusions.
} 
wages in (6'). What matters is that the parameter remains sizeable and statistically significant, leaving the substance of our conclusions unaltered.

\subsection{A random walk specification}

As an alternative way to assess the robustness of our conclusions about the negative impact of

UI on permanent wages, we now resort to an alternative model of the permanent wage, namely a random walk rather than random growth. The discussion of Section 3.1 showed that in the wage and income dynamics literature random walk is the main alternative to the random growth specification. In the random walk model, after labour market entry individual wages evolve through the arrival of infinitely lived shocks. Our permanent wage equation becomes:

$$
\begin{aligned}
w_{i c t}^{P}=\lambda_{c} \pi_{t}\left(r_{i e(t)}\right) ; & r_{i e(t)}=r_{i e(t-1)}+u_{i e(t)} ; \\
r_{i 0} \sim\left(0 ; \sigma_{r}^{2}\right) ; & u_{i e(t)} \sim\left(0 ; \sigma_{u c t}^{2}\right)
\end{aligned}
$$

where $e(t)$ is the level of experience of person $i$ in period $t$ and $r_{i 0}$ is the initial condition of the random walk. We model the impact of UI in the permanent wage by letting the variance of random walk innovations be a function of aggregate UI membership in cohort $c$ and period $t$

$$
\sigma_{u c t}^{2}=\sigma_{u}^{2} \exp \left(\phi F_{c t}\right)
$$

For the reasons discussed in Section 3.2, we use a common initial condition between UI members and non-members. There are two ways in which this alternative specification helps assessing the robustness of our conclusions. First, as with equation (6'), equation (6') does not require independence between individual UI and the permanent wage; rather it exploits variation over cohort-period cells in a difference-in-differences setup while controlling for cohort and time heterogeneity through the set of factor loadings $\lambda_{c}$ and $\pi_{t}$. Second, it does not assume a functional form for the individual wage profile and its interaction with UI membership. 
Results from the estimation of this model are reported in the fourth column of Table 5. The coefficient indexing the variance of permanent shocks with respect to UI membership is negative, confirming the result, obtained from the random growth specification, that inequality of permanent wages is lower with UI. It is also worth noting that, while leaving the substance of results unaltered with respect to the main model, transitory wage parameters show some sensitivity, possibly reflecting the similarity in specification between the random walk and the $\mathrm{AR}(1)$ and consequent difficulties in their separate identification.

\subsection{Differential wage or employment stability}

Our final set of robustness checks concentrates on the positive effect of UI membership on instability. We allow the effect to differ across groups of workers that are known to be characterised by different degrees of wage or employment instability. If the result from Section 5.2 was driven by the selection of more unstable workers into UI membership, then we expect to find it only within more unstable groups. We focus on two dimensions along which there may be relevant differences in the stability of the employment relationship. The first is the industry of affiliation, and we split metal manufacturing workers from the rest of the sample, because wages are more variable in this industry as there are more performancebased contracts. The second dimension is the local unemployment rate, and we distinguish low and high unemployment cells depending on the local unemployment rate being below or above the median in the unemployment distribution across cohorts and time periods, with the idea that there is more employment instability when unemployment is high. We interact these binary partitions with UI membership, and use this interaction to model wage instability, so that the variance of transitory shocks becomes

$$
\sigma_{\varepsilon c t}^{2}=\sigma_{\varepsilon}^{2} \exp \left(\psi_{1} P_{1} F_{c t}+\psi_{2} P_{2} F_{c t}\right)
$$


where $P_{1} F_{c t}$ and $P_{2} F_{c t}$ denote the incidence of UI in the more and less wage-stable group, respectively.

Results of this exercise are collected in the fifth and sixth columns of Table 5. We find that the positive relationship between UI fund membership and wage instability is not dependent on the specific group of workers considered. Even for the more stable groups of non-metal manufacturing workers and workers in low unemployment cells, there is a positive effect of UI on instability.

\section{Concluding remarks}

Our aim in this paper has been to determine how the wage dynamics of workers with unemployment insurance compare with those of the uninsured. We have considered the relationship between individual wage trajectories over the life cycle and membership of UI funds in Denmark. We have used data on the population of prime-aged male private sector employees for 24 years to decompose the wage process into its permanent and transitory components and we have characterised the impact of UI on each component.

We find that UI fund membership is associated with a reduction in wage growth heterogeneity that compresses the distribution of permanent wages. On the other hand, there is greater wage instability among UI fund members. We interpret these two findings as the symptoms of moral hazard effects associated with UI fund membership. More homogeneous life cycle profiles associated with UI fund membership are consistent with lower incentives to accumulate skills on-the-job. The greater earnings instability associated with UI fund membership may result from greater employment instability of insured workers. In principle our results could also stem from worker selection into membership of UI funds. We therefore subject the main findings to several robustness checks, all of which favour a moral hazard interpretation. 
These results add to the literature on the effect of unemployment benefit by showing that UI may exert some effect also on employed individuals wage dynamics. To the extent that the compression of permanent wages stems from lower effort and learning-by-doing, there may be a reduction of human capital accumulation and productivity associated with UI. Unemployment insurance exists to smooth consumption between periods of work by reducing transitory income fluctuations. The greater transitory wage variation in-work that we find partially offsets reduced income variation when unemployed for the insured. 
Appendix Table A1: Estimates of period specific loading factors in the baseline and main model

\begin{tabular}{|c|c|c|c|c|c|c|c|c|}
\hline & \multicolumn{4}{|c|}{ Baseline model } & \multicolumn{4}{|c|}{ Main model } \\
\hline & \multicolumn{2}{|c|}{ Permanent wages $\left(\pi_{t}\right)$} & \multicolumn{2}{|c|}{ Transitory wages $\left(\tau_{t}\right)$} & \multicolumn{2}{|c|}{ Permanent wages $\left(\pi_{t}\right)$} & \multicolumn{2}{|c|}{ Transitory wages $\left(\tau_{t}\right)$} \\
\hline & Coeff. & S.E. & Coeff. & S.E. & Coeff. & S.E. & Coeff. & S.E. \\
\hline $\begin{array}{c}\text { Year } \\
(1980=1)\end{array}$ & & & & & & & & \\
\hline 1981 & 0.951 & 0.003 & 0.870 & 0.002 & 0.947 & 0.003 & 0.914 & 0.003 \\
\hline 1982 & 0.886 & 0.004 & 0.825 & 0.003 & 0.869 & 0.004 & 0.885 & 0.004 \\
\hline 1983 & 0.875 & 0.004 & 0.805 & 0.003 & 0.855 & 0.004 & 0.857 & 0.004 \\
\hline 1984 & 0.868 & 0.004 & 0.789 & 0.003 & 0.851 & 0.004 & 0.824 & 0.004 \\
\hline 1985 & 0.853 & 0.004 & 0.793 & 0.004 & 0.842 & 0.004 & 0.821 & 0.004 \\
\hline 1986 & 0.844 & 0.004 & 0.792 & 0.004 & 0.833 & 0.004 & 0.811 & 0.004 \\
\hline 1987 & 0.794 & 0.004 & 0.783 & 0.004 & 0.764 & 0.005 & 0.797 & 0.004 \\
\hline 1988 & 0.783 & 0.004 & 0.773 & 0.004 & 0.752 & 0.005 & 0.763 & 0.004 \\
\hline 1989 & 0.768 & 0.004 & 0.762 & 0.003 & 0.734 & 0.005 & 0.737 & 0.004 \\
\hline 1990 & 0.776 & 0.004 & 0.749 & 0.003 & 0.738 & 0.005 & 0.713 & 0.004 \\
\hline 1991 & 0.744 & 0.004 & 0.748 & 0.003 & 0.707 & 0.005 & 0.712 & 0.004 \\
\hline 1992 & 0.708 & 0.004 & 0.738 & 0.003 & 0.665 & 0.005 & 0.707 & 0.004 \\
\hline 1993 & 0.750 & 0.004 & 0.690 & 0.003 & 0.695 & 0.006 & 0.641 & 0.004 \\
\hline 1994 & 0.761 & 0.004 & 0.701 & 0.003 & 0.703 & 0.006 & 0.643 & 0.004 \\
\hline 1995 & 0.739 & 0.004 & 0.661 & 0.004 & 0.682 & 0.006 & 0.590 & 0.004 \\
\hline 1996 & 0.715 & 0.004 & 0.643 & 0.004 & 0.657 & 0.005 & 0.579 & 0.004 \\
\hline 1997 & 0.665 & 0.004 & 0.657 & 0.004 & 0.614 & 0.004 & 0.602 & 0.005 \\
\hline 1998 & 0.657 & 0.004 & 0.704 & 0.005 & 0.608 & 0.004 & 0.656 & 0.005 \\
\hline 1999 & 0.619 & 0.004 & 0.726 & 0.005 & 0.573 & 0.004 & 0.690 & 0.005 \\
\hline 2000 & 0.595 & 0.004 & 0.752 & 0.005 & 0.552 & 0.004 & 0.722 & 0.006 \\
\hline 2001 & 0.567 & 0.004 & 0.779 & 0.005 & 0.526 & 0.004 & 0.752 & 0.006 \\
\hline 2002 & 0.523 & 0.003 & 0.784 & 0.005 & 0.487 & 0.003 & 0.755 & 0.006 \\
\hline 2003 & 0.498 & 0.003 & 0.801 & 0.005 & 0.467 & 0.003 & 0.764 & 0.006 \\
\hline
\end{tabular}


Appendix Table A2: Estimates of period specific loading factors in the baseline and main model

\begin{tabular}{|c|c|c|c|c|c|c|c|c|}
\hline \multirow{4}{*}{ Cohort $(1958=1)$} & \multicolumn{4}{|c|}{ Baseline model } & \multicolumn{4}{|c|}{ Main model } \\
\hline & \multicolumn{2}{|c|}{ Permanent wages $\left(\lambda_{c}\right)$} & \multicolumn{2}{|c|}{ Transitory wages $\left(\mu_{c}\right)$} & \multicolumn{2}{|c|}{ Permanent wages $\left(\lambda_{c}\right)$} & \multicolumn{2}{|c|}{ Transitory wages $\left(\mu_{c}\right)$} \\
\hline & Coeff. & S.E. & Coeff. & S.E. & Coeff. & S.E. & Coeff. & S.E. \\
\hline & & & & & & & & \\
\hline 1943 & 0.601 & 0.006 & 0.925 & 0.007 & 0.609 & 0.006 & 0.852 & 0.009 \\
\hline 1944 & 0.619 & 0.006 & 0.930 & 0.007 & 0.627 & 0.006 & 0.860 & 0.008 \\
\hline 1945 & 0.632 & 0.006 & 0.927 & 0.007 & 0.638 & 0.006 & 0.867 & 0.008 \\
\hline 1946 & 0.646 & 0.006 & 0.933 & 0.006 & 0.652 & 0.006 & 0.879 & 0.007 \\
\hline 1947 & 0.674 & 0.007 & 0.951 & 0.006 & 0.678 & 0.006 & 0.908 & 0.007 \\
\hline 1948 & 0.707 & 0.007 & 0.953 & 0.006 & 0.711 & 0.007 & 0.913 & 0.007 \\
\hline 1949 & 0.724 & 0.007 & 0.953 & 0.006 & 0.726 & 0.007 & 0.921 & 0.007 \\
\hline 1950 & 0.747 & 0.008 & 0.941 & 0.006 & 0.749 & 0.007 & 0.910 & 0.007 \\
\hline 1951 & 0.791 & 0.008 & 0.953 & 0.006 & 0.792 & 0.008 & 0.921 & 0.007 \\
\hline 1952 & 0.821 & 0.008 & 0.949 & 0.006 & 0.822 & 0.008 & 0.917 & 0.007 \\
\hline 1953 & 0.838 & 0.009 & 0.960 & 0.006 & 0.840 & 0.008 & 0.932 & 0.007 \\
\hline 1954 & 0.861 & 0.009 & 0.963 & 0.006 & 0.861 & 0.008 & 0.942 & 0.007 \\
\hline 1955 & 0.905 & 0.009 & 0.971 & 0.006 & 0.905 & 0.009 & 0.951 & 0.007 \\
\hline 1956 & 0.940 & 0.009 & 0.977 & 0.006 & 0.939 & 0.009 & 0.962 & 0.007 \\
\hline 1957 & 0.976 & 0.010 & 0.989 & 0.006 & 0.976 & 0.009 & 0.976 & 0.006 \\
\hline 1959 & 1.026 & 0.010 & 0.996 & 0.006 & 1.024 & 0.010 & 1.003 & 0.006 \\
\hline 1960 & 1.020 & 0.010 & 1.092 & 0.006 & 1.031 & 0.010 & 1.086 & 0.007 \\
\hline 1961 & 1.036 & 0.010 & 1.092 & 0.006 & 1.046 & 0.010 & 1.093 & 0.007 \\
\hline 1962 & 1.053 & 0.011 & 1.119 & 0.007 & 1.067 & 0.010 & 1.133 & 0.008 \\
\hline 1963 & 1.068 & 0.011 & 1.134 & 0.007 & 1.086 & 0.010 & 1.161 & 0.008 \\
\hline 1964 & 1.102 & 0.012 & 1.151 & 0.007 & 1.123 & 0.011 & 1.189 & 0.008 \\
\hline 1965 & 1.102 & 0.013 & 1.181 & 0.007 & 1.136 & 0.012 & 1.230 & 0.008 \\
\hline 1966 & 1.058 & 0.013 & 1.199 & 0.007 & 1.102 & 0.012 & 1.272 & 0.009 \\
\hline 1967 & 0.964 & 0.014 & 1.229 & 0.007 & 1.031 & 0.012 & 1.319 & 0.009 \\
\hline 1968 & 0.777 & 0.016 & 1.267 & 0.008 & 0.891 & 0.013 & 1.369 & 0.010 \\
\hline 1969 & & & 1.339 & 0.008 & & & 1.462 & 0.010 \\
\hline 1970 & & & 1.310 & 0.008 & & & 1.433 & 0.011 \\
\hline 1971 & 0.356 & 0.020 & 1.280 & 0.008 & 0.634 & 0.011 & 1.442 & 0.011 \\
\hline 1972 & & & 1.248 & 0.008 & & & 1.507 & 0.011 \\
\hline 1973 & & & 1.214 & 0.008 & & & 1.529 & 0.012 \\
\hline
\end{tabular}




\section{References}

Altonji, J. G. and Segal, L. M. (1996) Small-Sample Bias in GMM Estimation of Covariance Structures, Journal of Business \& Economic Statistics, 14(3).

Altonji, J., Smith A. and Vidangos I. (2009) Modeling Earnings Dynamics, National Bureau of Economic Research Working Paper 14743.

Alvarez, J., Browning, M. and Ejrnæs, M. (2010) Modelling Income Processes with Lots of Heterogeneity, Review of Economic Studies, 77(4).

Andersen, T.M. and Svarer, M. (2007) Flexicurity: Labour Market Performance in Denmark, Working paper 2007-9, Economics Department, Aarhus University.

Andersen, T.M, Dalum B., Linderoth H., Smith V. and Westergård-Nielsen N. (2011) The Danish Economy. An International Perspective. DJØF Publishing Copenhagen.

Anderson, D.A. (1994) Compensating Wage Differentials and the Optimal Provision of Unemployment Insurance, Southern Economic Journal, 60(3).

Anderson, P.A. and Meyer, B.D. (2000) The Effects of Unemployment Insurance Payroll Tax on Wages, Employment, Claims and Denials, Journal of Public Economics, 78(1-2).

Baker, M. (1997) Growth Rate Heterogeneity and the Covariance Structure of Life cycle Earnings, Journal of Labor Economics, 15(2).

Baker M and Solon G (2003) Earnings Dynamics and Inequality among Canadian Men, 1976-1992: Evidence from Longitudinal Income Tax Records Journal of Labor Economics, 21(2).

Blundell, R., Pistaferri, L. and Preston, I. (2008) Consumption Inequality and Partial Insurance, American Economic Review, 98(5).

Burdett, K. (1978) The Testing and Sorting Functions of Higher Education, Journal of Public Economics, 10(1). 
Burdett, K., Carrillo-Tudela, C. and Coles, M. (2011) Human Capital Accumulation and Labour Market Equilibrium, International Economic Review, 52(3).

Cappellari, L. (2004) The Dynamics and Inequality of Italian Men's Earnings: Long-term Changes or Transitory Fluctuations?, Journal of Human Resources, 39(4).

Chamberlain, G. (1984) Panel Data, in Griliches Z and Intriligator M (eds.), Handbook of Econometrics, vol. 2, Elsevier.

Chetty, R. (2008) Moral Hazard versus Liquidity and Optimal Unemployment Insurance, Journal of Political Economy, 116(2).

Clasen, J. and Viebrock, E. (2008) Voluntary Unemployment Insurance and Trade Union Membership: Investigating the Connections in Denmark and Sweden, Journal of Social Policy, 37(3)

Currie, J. and Madrian, B.C. (1999) Health, Health Insurance and the Labor Market, Ashenfelter, O. and Card, D. (eds), Handbook of Labor Economic, vol. 3, Elsevier.

Dahl, C.M, le Maire, D and Munch, J.R. (2009) Wage Dispersion and Decentralised Bargaining, Discussion Paper 09-15, Economics Department, University of Copenhagen.

Dickens, R. (2000) The Evolution of Individual Male Earnings in Great Britain: 1975-95, Economic Journal, 110(460).

Feldstein, M. and Poterba, J. (1984) Unemployment Insurance and Reservation Wages, Journal of Public Economics, 23(1-2).

Friedman, M. (1957) A Theory of the Consumption Function, NBER Books, National Bureau of Economic Research.

Gibbons, R. and Waldman, M. (1999) A Theory Of Wage And Promotion Dynamics Inside Firms, The Quarterly Journal of Economics, 114(4). 
Gladden, T. And Taber, C. (2009) The Relationship between Wage Growth and Wage Levels, Journal of Applied Econometrics, 24(6).

Gottschalk P. and Moffitt R. (1994) The Growth of Earnings Instability in the U.S. Labor Market, Brookings Papers on Economic Activity 25(2).

Gruber, J. (1997) The Consumption Smoothing Benefits of Unemployment Insurance, American Economic Review, 87 (1).

Guiso, L., Pistaferri, L. and Schivardi, F. (2005) Insurance within the Firm, Journal of Political Economy, 113(5).

Haider SJ (2001) Earnings Instability and Earnings Inequality of Males in the United States: 1967-1991 Journal of Labor Economics, 19(4).

Hause, J. C. (1980) The Fine Structure of Earnings and the On-the-Job Training Hypothesis. Econometrica, 48(4).

Heckman, J., Lochner, L. and Todd, P. (2008) Earnings Functions and Rates of Return, Journal of Human Capital, 2(1).

Ibsen R. and Westergaard-Nielsen (2008) Danish "Flexicurity": Are the Secure Flexible and the Flexible Secure?, CCP, Aarhus School of Business, University of Aarhus, unpublished manuscript.

Kaplan, G. and Violante, G.L. (2010) How Much Consumption Insurance beyond SelfInsurance? American Economic Journal: Macroeconomics, 2(4).

Lalive, R. and J. Zweimüller (2004) Benefit Entitlement and Unemployment Duration: Accounting for Policy Endogeneity, Journal of Public Economics, 88(12).

Lillard, L. and Weiss, Y. (1979) Components of Variation in Panel Earnings Data: American Scientists, 1960-70, Econometrica, 47(2).

Lillard, L. and Willis, R. (1978) Dynamic Aspects of Earning Mobility, Econometrica, 46(5). 
Low, H., Meghir C.and Pistaferri L. (2010) Wage Risk and Employment Risk over the Life Cycle, American Economic Review, 100(4).

MaCurdy, T. E. (1982) The Use of Time Series Processes to Model the Error Structure of Earnings in a Longitudinal Data Analysis, Journal of Econometrics, 18(1).

Meghir, C. and Pistaferri, L. (2004) Income Variance Dynamics and Heterogeneity, Econometrica, 72(1).

Meghir, C. and Pistaferri, L. (2011) Earnings, Consumption, and Life Cycle Choices, in Ashenfelter, O. and Card, D. (eds) Handbook of Labor Economics vol.4B.

Mincer, J. (1974) Schooling, Experience and Earnings, Columbia University Press.

Moffitt R. and Gottschalk P. (2012) Trends in the Transitory Variance of Male Earnings in the U.S., 1970-2004, Journal of Human Resources, 47(1).

Neumann, G., Pedersen P.J. and N. Westergård-Nielsen (1991), Long-run International Trends in Aggregate Unionization, European Journal of Political Economy, 7(1).

Prat, J. (2010) The Rate of Learning-by-Doing: Estimates from a Search and Matching Model, Journal of Applied Econometrics, 25(6).

Rubinstein, Y. and Weiss, Y. (2006) Post Schooling Wage Growth: Investment, Search and Learning, in Hanushek E., A. and Welch, F. (eds.) Handbook of the Economics of Education, Elsevier.

Shimer, R. and Werning, I. (2007) Reservation Wages and Unemployment Insurance, Quarterly Journal of Economics, 122(3).

Shin, D. and Solon, G. (2011) Trends in Men's Earnings Volatility: What does the Panel Study of Income Dynamics Show?, Journal of Public Economics, 95(7-8).

Tatsiramos, K. (2009) Unemployment Insurance in Europe: Unemployment Duration and Subsequent Employment Stability, Journal of the European Economic Association, 2009, 7(6). 
Topel, R.H. (1984) Equilibrium Earnings, Turnover and Unemployment: New Evidence, Journal of Labor Economics, 2(4). 


$\begin{array}{lllllll}1980 & 1985 & 1990 & 1995 & 2000 & 2003 & \text { All years }\end{array}$

Observations $\begin{array}{lllllll}315546 & 450544 & 524817 & 606268 & 617047 & 563419 & 12469693\end{array}$

UI incidence $\begin{array}{lllllll}0.8 & 0.84 & 0.9 & 0.95 & 0.89 & 0.89 & 0.89\end{array}$

Average real wage (cpi 2000) All

$\begin{array}{lllllll}155.75 & 162.3 & 188.35 & 189.13 & 202 & 200.28 & 184.94\end{array}$ $\begin{array}{llllllll}\text { UI members } & 155.12 & 160.94 & 186.86 & 188.09 & 198.67 & 197.07 & 183.51\end{array}$ $\begin{array}{llllllll}\text { UI non-member } & 158.36 & 169.59 & 201.52 & 207.7 & 229.7 & 226.72 & 196.52\end{array}$

S.D. log wage

$\begin{array}{lccccccc}\text { All } & 0.27 & 0.28 & 0.3 & 0.32 & 0.33 & 0.33 & 0.32 \\ \text { UI members } & 0.25 & 0.26 & 0.28 & 0.31 & 0.31 & 0.32 & 0.3 \\ \text { UI non-member } & 0.33 & 0.37 & 0.42 & 0.46 & 0.45 & 0.45 & 0.43\end{array}$

Potential

$\begin{array}{lccccccc}\text { All } & 8.6 & 10.79 & 13.23 & 15.53 & 18.46 & 20.37 & 14.71 \\ \text { UI members } & 8.54 & 10.83 & 13.39 & 15.75 & 18.83 & 20.67 & 15 \\ \text { UI non-member } & 8.85 & 10.61 & 11.86 & 11.61 & 15.41 & 17.91 & 12.39\end{array}$

S.D. log wage

All

$0.25 \quad 0.26$

0.28

0.29

0.32

0.36

0.29

experience $=10$

UI members

$0.24 \quad 0.25$

0.27

0.28

0.30

0.34

0.28

UI non-member

$0.29 \quad 0.32$

0.39

0.39

0.41

0.45

0.36

S.D. log wage All

$\begin{array}{llllll}0.28 & 0.33 & 0.33 & 0.34 & 0.34 & 0.32\end{array}$

experience $=20$

UI members

0.25

0.31

0.32

0.32

0.32

0.31

UI non-member

$0.34 \quad 0.4$

$\begin{array}{lll}0.44 & 0.46 \quad 0.46\end{array}$

0.41 
Table 2: UI incidence and UI transition rates

\begin{tabular}{|c|c|c|c|c|c|c|c|c|}
\hline \multirow{3}{*}{ Total } & & \multirow[t]{2}{*}{ Incidence } & \multicolumn{3}{|c|}{ Entry rates } & \multicolumn{3}{|c|}{ Exit rates } \\
\hline & & & All & Falling unem. & Rising unem. & All & Falling unem. & Rising unem. \\
\hline & & 89.06 & 12.23 & 8.29 & 15.22 & 0.74 & 1.00 & 0.33 \\
\hline \multirow[t]{8}{*}{ Age } & $18-20$ & 50.94 & 25.80 & 24.56 & 27.03 & 1.36 & 1.59 & 1.36 \\
\hline & $21-25$ & 83.38 & 24.55 & 20.35 & 26.00 & 0.85 & 1.29 & 0.63 \\
\hline & $26-30$ & 88.60 & 14.14 & 11.22 & 14.37 & 0.86 & 1.26 & 0.43 \\
\hline & $31-35$ & 89.20 & 10.68 & 8.10 & 10.94 & 0.85 & 1.18 & 0.37 \\
\hline & $36-40$ & 88.72 & 9.41 & 6.77 & 10.49 & 0.76 & 1.07 & 0.29 \\
\hline & $41-45$ & 90.48 & 10.22 & 5.70 & 14.76 & 0.58 & 0.88 & 0.07 \\
\hline & $46-50$ & 92.53 & 10.81 & 5.39 & 26.05 & 0.57 & 0.72 & 0.06 \\
\hline & $51-55$ & 92.74 & 4.93 & 4.93 & 0.00 & 0.60 & 0.60 & 0.00 \\
\hline \multirow[t]{5}{*}{ Experience } & $<1$ & 39.34 & 15.28 & 13.97 & 16.55 & 3.25 & 4.08 & 2.75 \\
\hline & $1--5$ & 74.67 & 23.83 & 18.96 & 27.14 & 1.29 & 1.80 & 0.90 \\
\hline & $5--10$ & 88.34 & 13.15 & 9.52 & 14.09 & 0.91 & 1.31 & 0.52 \\
\hline & $10--20$ & 89.56 & 9.67 & 6.36 & 10.87 & 0.73 & 1.09 & 0.25 \\
\hline & $>20$ & 92.56 & 9.69 & 5.59 & 19.60 & 0.49 & 0.60 & 0.03 \\
\hline \multirow[t]{3}{*}{ Education } & Below secondary & 89.82 & 13.29 & 9.40 & 16.30 & 0.83 & 1.13 & 0.41 \\
\hline & Secondary & 89.04 & 12.32 & 8.30 & 15.12 & 0.68 & 0.93 & 0.30 \\
\hline & College & 87.52 & 10.10 & 6.65 & 13.59 & 0.83 & 1.09 & 0.28 \\
\hline \multirow[t]{2}{*}{ Occupation } & Manual & 91.45 & 16.05 & 10.94 & 16.14 & 0.32 & 0.39 & 0.32 \\
\hline & Non manual & 84.35 & 14.01 & 7.87 & 14.61 & 0.36 & 0.44 & 0.35 \\
\hline \multirow[t]{8}{*}{ Industry } & Agriculture and Extraction & 76.29 & 10.78 & 7.82 & 12.55 & 1.21 & 1.54 & 0.76 \\
\hline & Manufacturing & 94.76 & 17.61 & 12.25 & 21.75 & 0.46 & 0.65 & 0.19 \\
\hline & Energy, Gas and Water & 93.43 & 12.49 & 7.47 & 13.25 & 0.38 & 0.55 & 0.17 \\
\hline & Construction & 94.80 & 18.30 & 13.24 & 23.63 & 0.59 & 0.83 & 0.23 \\
\hline & Hotel and Restaurant & 86.43 & 11.68 & 7.47 & 14.22 & 0.96 & 1.30 & 0.49 \\
\hline & Transport and Communic. & 87.45 & 11.82 & 8.13 & 15.43 & 0.96 & 1.25 & 0.43 \\
\hline & Finance & 76.53 & 9.03 & 5.30 & 11.82 & 1.12 & 1.47 & 0.44 \\
\hline & Personal Service & 87.37 & 9.14 & 6.90 & 15.26 & 1.13 & 1.44 & 0.31 \\
\hline
\end{tabular}

Note: Percentage points. Transition rates are calculated on the populations at risks of experiencing the trans
unemployment years= 1980-1983 and 1988-1993. Statistics by occupation refer to the years 1980-1995. 
Table 3: Baseline model and model with UI membership: Core parameter estimates

Baseline Model Main Model

$\begin{array}{rcccc}\text { Permanent wage } & \text { Coeff. } & \text { S.E. } & \text { Coeff. } & \text { S.E. } \\ \sigma_{\alpha}^{2} & 0.0079 & 0.00073 & 0.0157 & 0.00071 \\ \sigma_{\beta}^{2} & 0.0008 & 0.00002 & 0.0012 & 0.00004 \\ \sigma_{\alpha \beta}^{2} & -0.0034 & 0.00010 & -0.0041 & 0.00010 \\ \sigma_{\delta}^{2} & & & 0.0016 & 0.00004 \\ \sigma_{\beta \delta} & & -0.0009 & 0.00002 \\ \text { Transitory wage } & & & & \\ \sigma_{0}^{2} & 0.0628 & 0.00059 & 0.0551 & 0.00061 \\ \sigma_{\varepsilon}^{2} & 0.0335 & 0.00041 & 0.0017 & 0.00015 \\ \psi & & & 3.3718 & 0.10032 \\ \rho & 0.7737 & 0.00089 & 0.7228 & 0.00119\end{array}$

Note: the model includes flexible shifters for time periods and birth cohorts on each wage component, estimates are reported in Tables A1 and A2. The model is estimated on 12469693 wage observations, corresponding to 811651 individuals observed between 1980 and 2003, and 6895 second moments of the within cohort intertemporal wage distribution. 
Table 4. Insurance fund membership as a function of lagged wage growth and lagged wage volatility

Estimator Explanatory variable of interest Number of years of previous non-membership

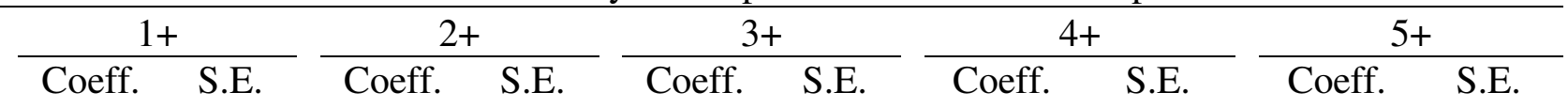

\begin{tabular}{|c|c|c|c|c|c|c|c|c|c|c|c|}
\hline FE logit & lagged wage growth & 0.1450 & 0.0279 & 0.0532 & 0.0234 & 0.0074 & 0.0226 & 0.0201 & 0.0223 & 0.0117 & 0.0223 \\
\hline FE OLS & lagged volatility (squared)/1000 & -0.0053 & 0.0008 & -0.0050 & 0.0007 & -0.0047 & 0.0006 & -0.0041 & 0.0005 & -0.0034 & 0.0005 \\
\hline FE OLS & lagged volatility (absolute)/1000 & -0.7526 & 0.0921 & -0.7888 & 0.0783 & -0.7754 & 0.0673 & -0.6922 & 0.0593 & -0.5837 & 0.0533 \\
\hline
\end{tabular}


Table 5: Sensitivity analysis on wage dynamics models

\begin{tabular}{cc}
$\begin{array}{c}\text { Baseline model on } \\
\text { UI switchers } \\
\text { sample }\end{array}$ & $\begin{array}{c}\text { Main model on } \\
\text { industry-education- } \\
\text { unemployment } \\
\text { adjusted wages }\end{array}$ \\
\hline
\end{tabular}

\begin{tabular}{|c|c|c|c|}
\hline $\begin{array}{l}\text { Main model with } \\
\text { aggregate UI } \\
\text { indicator in } \\
\text { permanent wages }\end{array}$ & $\begin{array}{c}\text { Random walk } \\
\text { permanent wage }\end{array}$ & $\begin{array}{l}\text { Main model with } \\
\text { industry effects in } \\
\text { the transitory } \\
\text { component }\end{array}$ & $\begin{array}{c}\text { Main model with } \\
\text { unemployment } \\
\text { effects in the } \\
\text { transitory } \\
\text { component }\end{array}$ \\
\hline S.E. & Coeff. & Coeff. & Coeff. \\
\hline
\end{tabular}

\section{Permanent \\ wage}

Coeff. S.E.

Coeff. S.E.

Coeff. S.E.

Coeff.

$\begin{array}{ccccccc}\sigma_{\alpha}^{2} & 0.0012 & 0.00103 & 0.0193 & 0.00069 & 0.0183 & 0.00073 \\ \sigma_{\beta}^{2} & 0.0009 & 0.00003 & 0.0012 & 0.00003 & 0.0008 & 0.00004 \\ \sigma_{r}^{2} & & & & & & \\ \sigma_{u}^{2} & & & & & & \\ \sigma_{\alpha \beta} & -0.0036 & 0.00015 & -0.0037 & 0.00009 & -0.0045 & 0.00010 \\ \sigma_{\delta}^{2} & & & 0.0016 & 0.00004 & 0.0018 & 0.00004 \\ \sigma_{\beta \delta} & & & -0.0010 & 0.00002 & -0.0007 & 0.00003 \\ \phi & & & & & & \end{array}$

Transitory

wage

$\begin{array}{rrrrrrr}\sigma_{0}^{2} & 0.0705 & 0.00092 & 0.0532 & 0.00057 & 0.0549 & 0.00059 \\ \sigma_{\varepsilon}^{2} & 0.0376 & 0.00067 & 0.0021 & 0.00018 & 0.0028 & 0.00025 \\ \psi & & & 3.0810 & 0.09535 & 2.7604 & 0.10050 \\ \psi_{1} & & & & & & \\ \psi_{2} & & & & & & \\ \rho & 0.7558 & 0.00144 & 0.6974 & 0.00117 & 0.7266 & 0.00111\end{array}$

$\begin{array}{ll}0.0064 & 0.0002 \\ 0.0107 & 0.0005\end{array}$

$\begin{array}{llll}0.0167 & 0.00071 & 0.0156 & 0.0007 \\ 0.0012 & 0.00004 & 0.0012 & 0.0000\end{array}$

$\begin{array}{cccc}-0.0041 & 0.00010 & -0.0041 & 0.0001 \\ 0.0017 & 0.00004 & 0.0016 & 0.00004 \\ -0.0010 & 0.00003 & -0.0009 & 0.00003\end{array}$

$-0.2366 \quad 0.0560$

$\begin{array}{rrrrrr}0.0595 & 0.0011 & 0.0532 & 0.00062 & 0.0552 & 0.0006 \\ 0.0003 & 0.00005 & 0.0013 & 0.00012 & 0.0017 & 0.0002 \\ 5.4550 & 0.1654 & & & & \\ & & 14.8291 & 1.31928 & 3.3322 & 0.1015 \\ & & 2.9606 & 0.11247 & 3.3716 & 0.1004 \\ 0.5439 & 0.0019 & 0.7183 & 0.00125 & 0.7224 & 0.0012\end{array}$

0.1370

0.0993

0.0995

Note: All models includes flexible shifters for time periods and birth cohorts on each wage component. With the exception of the model on the UI switchers sample, all models are estimated on 12469693 wage observations, corresponding to 811651 individuals observed between 1980 and 2003 , and 6895 second moments of the within cohort intertemporal wage distribution. The UI switchers sample is based on 301214 individuals observed between 1980 and 2003 , corresponding to 4751070 wage observations. 
Figure 1: Wage variance and covariances by year and potential labour market experience
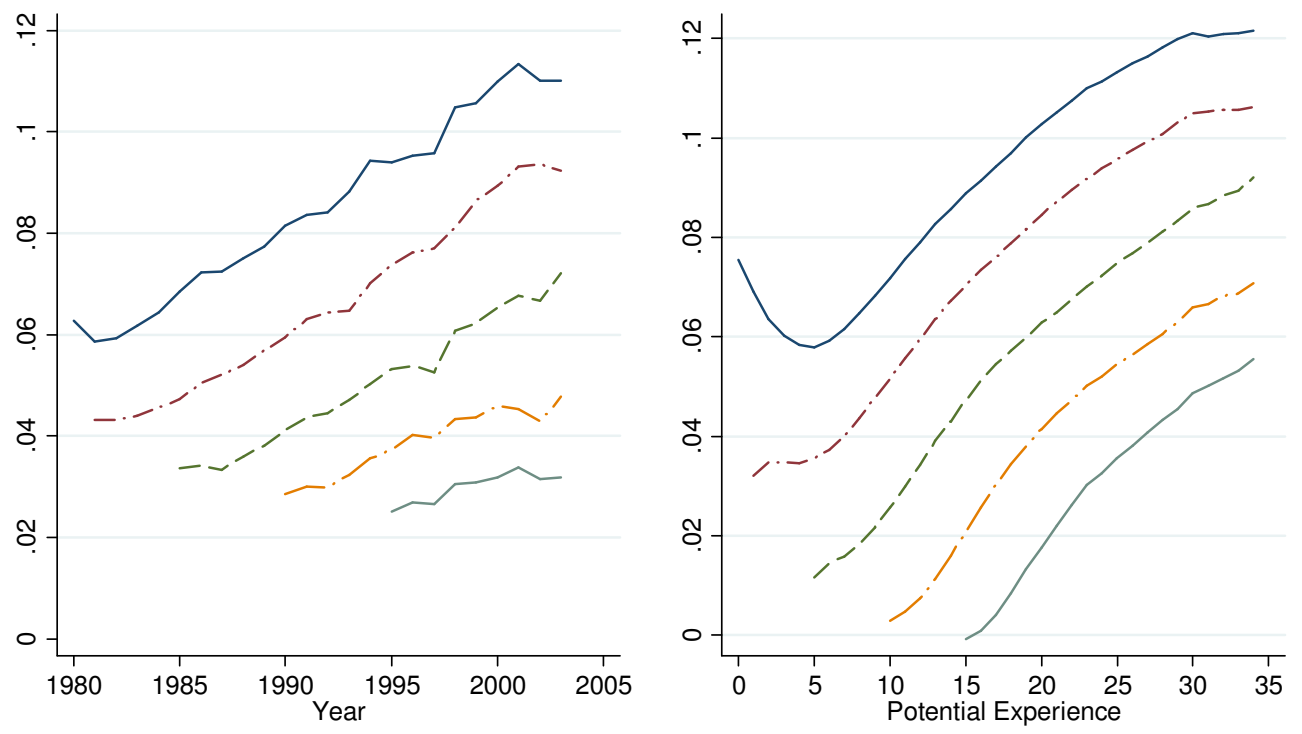

$\begin{aligned}- \text { Variance } & -\cdot-\cdot-\cdot \operatorname{Cov}(\mathrm{t}, \mathrm{t}-1) \\ -----\operatorname{Cov}(\mathrm{t}, \mathrm{t}-5) & -\cdot-\cdot \operatorname{Cov}(\mathrm{t}, \mathrm{t}-10) \\ -\operatorname{Cov}(\mathrm{t}, \mathrm{t}-15) & \end{aligned}$


Figure 2: Predictions of wage variance components by year and potential labour market experience
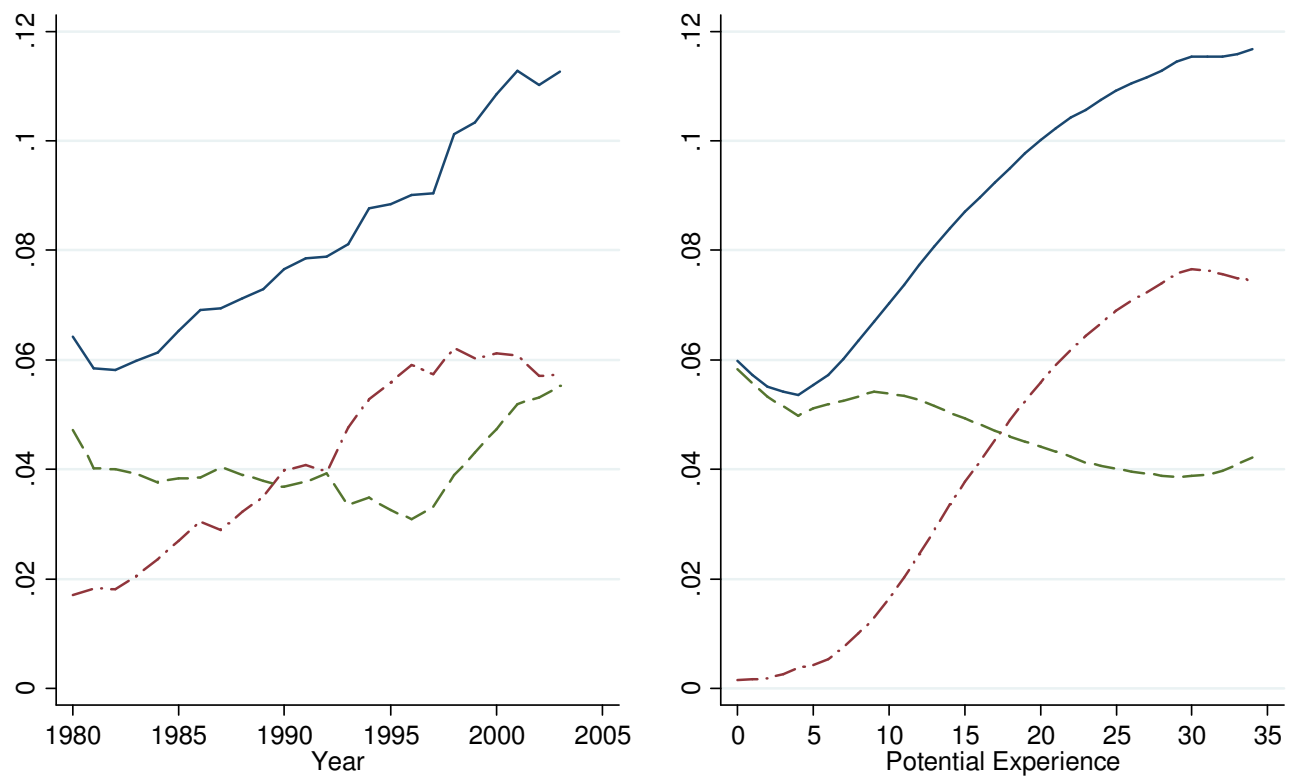

Total variance

-.-.-.- Permanent variance

Transitory variance 
Figure 3: Components of wage inequality over the life cycle and UI membership
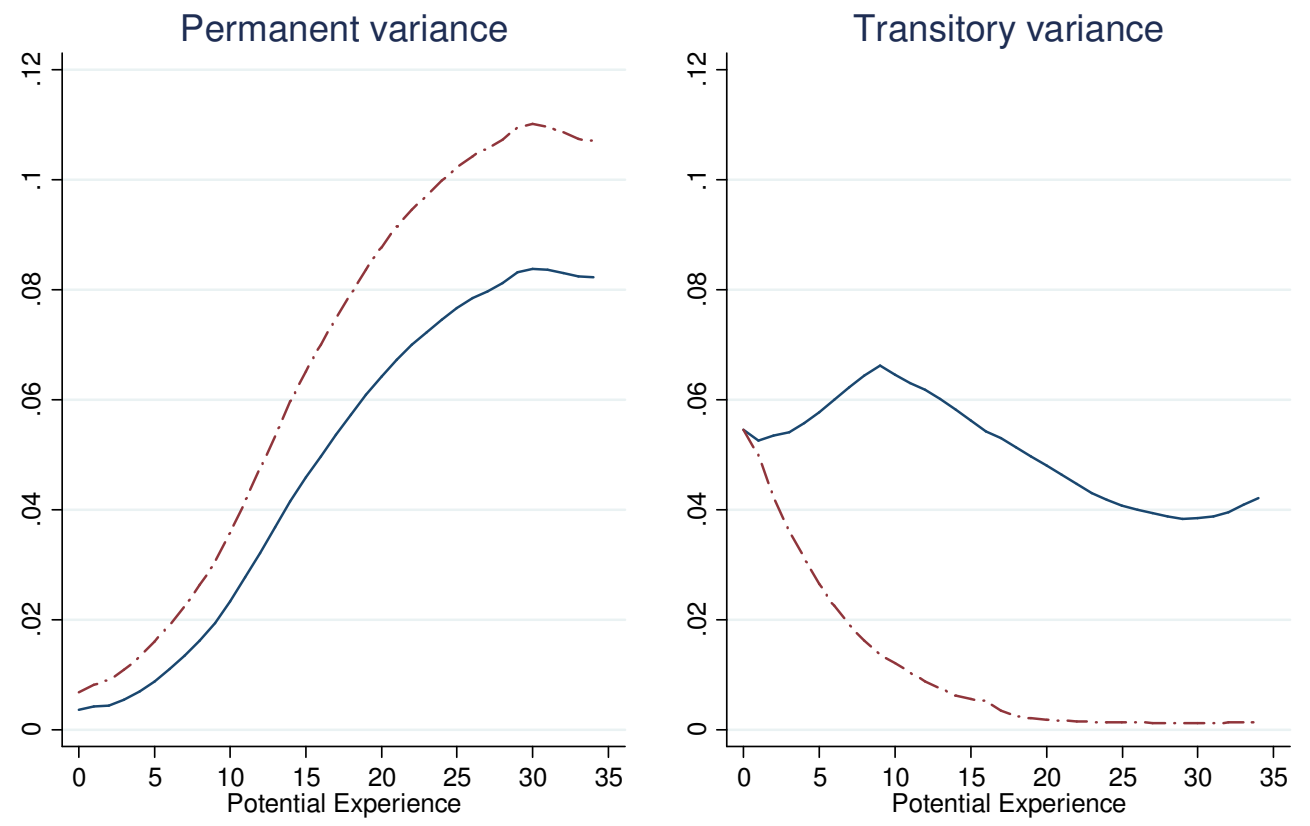

UI member -.-.-.-- UI non-member 